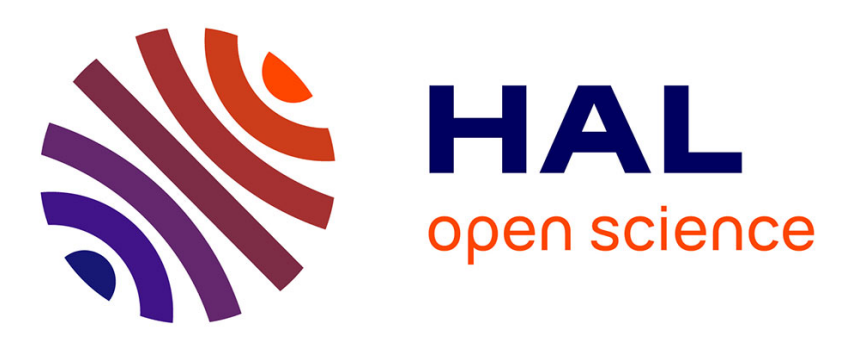

\title{
Recent trends in the development of sustainable catalytic systems for the oxidative cleavage of cycloalkenes by hydrogen peroxide
}

Tony Cousin, Gregory Chatel, Nathalie Kardos, Bruno Andrioletti, Micheline Draye

\section{To cite this version:}

Tony Cousin, Gregory Chatel, Nathalie Kardos, Bruno Andrioletti, Micheline Draye. Recent trends in the development of sustainable catalytic systems for the oxidative cleavage of cycloalkenes by hydrogen peroxide. Catalysis Science \& Technology, 2019, 9 (19), pp.5256-5278. 10.1039/C9CY01269A . hal02357883

\section{HAL Id: hal-02357883 \\ https://hal.science/hal-02357883}

Submitted on 2 Apr 2021

HAL is a multi-disciplinary open access archive for the deposit and dissemination of scientific research documents, whether they are published or not. The documents may come from teaching and research institutions in France or abroad, or from public or private research centers.
L'archive ouverte pluridisciplinaire HAL, est destinée au dépôt et à la diffusion de documents scientifiques de niveau recherche, publiés ou non, émanant des établissements d'enseignement et de recherche français ou étrangers, des laboratoires publics ou privés. 


\section{Catalysis Science \& Technology}

MINIREVIEW

\section{Recent trends in the development of sustainable catalytic systems for the oxidative cleavage of cycloalkenes by hydrogen peroxide}

Received 00th January 20xx Accepted 00th January 20xx

DOI: $10.1039 / \times 0 \times x 00000 x$

www.rsc.org/

\begin{abstract}
Tony Cousin ${ }^{\mathrm{a}, \mathrm{b}}$, Gregory Chatel ${ }^{\mathrm{a}}$, Nathalie Kardos ${ }^{\mathrm{a}}$, Bruno Andrioletti ${ }^{\mathrm{b} \dagger}$ and Micheline Draye ${ }^{\mathrm{a} \dagger}$
Dicarboxylic acids constitute one of the most important oxygenated intermediates in the chemical industry originating a wide range of daily products: fibers, pharmaceuticals, cosmetics, lubricants, pesticides and plasticizers. A major part of their large scale production relies on the oxidative cleavage processes of unsaturated acids and cyclic olefins but suffers from severe drawbacks such as the use of harmful compounds, the need of specific set-ups to produce oxidants, expensive catalysts and energy consuming conditions. In the context of the development of sustainable oxidations, hydrogen peroxide has witnessed a growing interest thanks to its multiple benefits to replace conventional oxidants: low toxicity, no need of energetic conditions to perform catalytic oxidations and generation of benign $\mathrm{H}_{2} \mathrm{O}$ as by-product. The present review aims at bringing a critical view on the development of catalytic systems for the $\mathrm{H}_{2} \mathrm{O}_{2}$-mediated oxidative cleavage of cycloalkenes toward green chemistry criteria. Different transition-metal-based catalysts investigated for the reaction will be discussed with a special emphasis on tungsten. Next, the performances of different heterogeneous and homogenous W-based systems on the oxidative cleavage of various cycloolefins will be presented. More specifically, their relevance towards sustainable oxidations will be assessed by studying key reaction features: solvent, $\mathrm{H}_{2} \mathrm{O}_{2}$ amount, reaction time and catalysts synthesis, recoverability and activity. The main challenges regarding the oxidative cleavage of medium-sized cycloalkenes with $\mathrm{W}-\mathrm{H}_{2} \mathrm{O}_{2}$ systems will be also exposed. At last, the potential of ultrasound as unconventional activation method will be pointed out to overcome the limits encountered with the conventionnal thermal heating leading to even more environmentally-friendly cycloalkene oxidative cleavage.
\end{abstract}

\section{Introduction}

Oxidation reactions are known to be part of the most important processes in chemical industry. ${ }^{1-4}$ Their ability to convert carbon compounds into functionalized molecules enables the production of a wide variety of everyday life compounds. Among the products obtained through oxidation processes, dicarboxylic acids show a great interest for the production of value added polymers. They represent important feedstock in the manufacture of polyesters and polyamides and find applications in various fields: fibers, lubricants, pharmaceuticals, pesticides, cosmetics and plasticizers. $^{5,6}$ The main processes developed for the manufacture of dicarboxylic acids lie on oxidative cleavage., This reaction based on the cleavage of a carbon-carbon double bond using an oxidant leads to various oxygenated compounds according to the functional groups borne by the double bond and the experimental conditions: ketones, aldehydes and carboxylic acids (Scheme 1).
Scheme 1: General scheme for oxidative cleavage reaction.

Industrially, dicarboxylic acids are produced through oxidative cleavage of two kinds of molecules: cyclic olefins or unsaturated carboxylic acids.

For instance, the oxidative cleavage of oleic acid by ozonolysis leads to azelaic acid (Scheme 2 a)). The two-step process, firstly patented at the end of the 50's by Emery Industries ${ }^{7}$, allows the production of up to 10,000 tons/year of azelaic acid along with pelargonic acid to deserve the fields of resins,

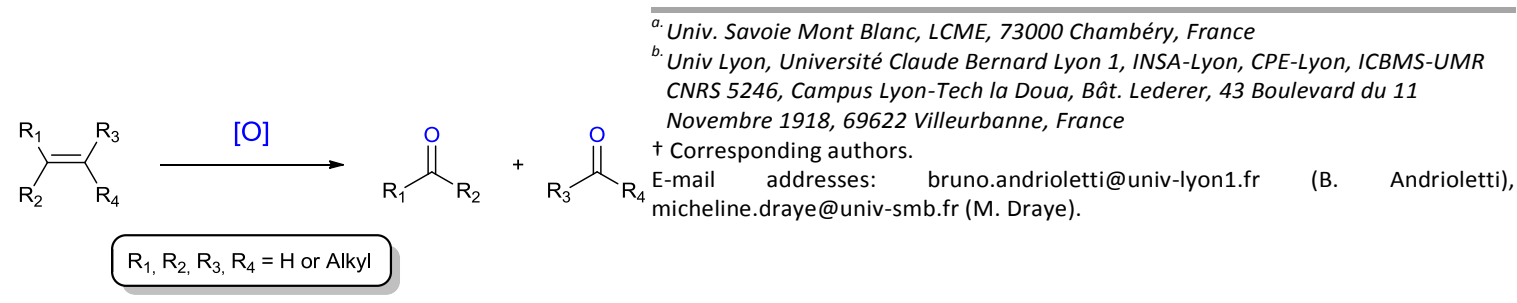


lubricants or auto parts. ${ }^{1,5,8,9}$ Also, one of the oldest large scale oxidation process still in operation is the manufacture of adipic acid. Its synthesis is based on a two-step reaction involving the air oxidation of cyclohexane to cyclohexanol or cyclohexanone followed by the oxidative cleavage of one of them or a mixture of both (Ketone + Alcohol: KA Oil) with nitric acid (Scheme 2 b)). Despite the low conversion required for the first step (not exceeding $7 \%)^{10}$ to achieve relatively high selectivity in KA oil, this process succeeds to reach average yields of $95 \%$ through cyclohexane recycling. This process patented by DuPont leads to an actual adipic acid production of 2.6 million ton/year and allows this compound to be the most important commercially available aliphatic dicarboxylic acid. ${ }^{5,6,11,12}$ The production of adipic acid through oxidative cleavage is mainly dedicated to the synthesis of Nylon 6,6, but also supplies the manufacturers of plasticizers, lubricants and polyurethane resins. ${ }^{5,6,12}$

a)

Ozonolysis of oleic acid

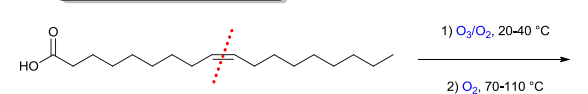

2) $0_{2}, 70-110^{\circ} \mathrm{C}$

b)

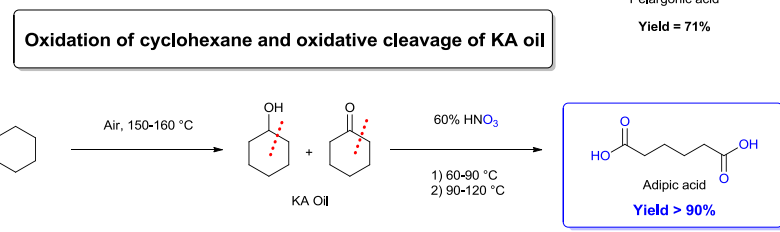

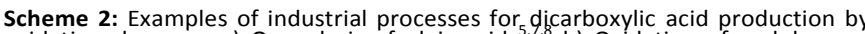
oxidative cleavage: a) Ozonolysis of oleic acid ${ }^{5,7,8}$ b) Oxidation of cyclohexane and oxidative cleavage of cyclohexanol/cyclohexanone (KA Oil)

Despite the large volumetric amounts of chemicals sold worldwide, these processes suffer from severe drawbacks such as the use of corrosive and dangerous compounds, the need of specific instruments to produce oxidants (corona discharge ozone generator, UV instruments) high temperatures and expensive catalysts.

Specifically, one of the key environmental issue that adipic acid industry still faces is the $\mathrm{N}_{2} \mathrm{O}$ abatement. Indeed, after $\mathrm{HNO}_{3}$ oxidation of KA oil, up to 400,000 tons/year of $\mathrm{N}_{2} \mathrm{O}$ are generated. Such a large amount of nitrous oxide thus represents $8 \%$ of the total anthropogenic production of this greenhouse gas. $^{13,14}$ These emissions result in harmful consequences on the environment: ozone depletion, smog, acid rain and global warming. ${ }^{15,16}$ Over the years, most of industries achieved to reduce their $\mathrm{N}_{2} \mathrm{O}$ emission by $80 \%$ by switching from air venting to recycling or decomposing nitrous oxide by thermal or catalytic pathways. ${ }^{10,12,16,17}$ In spite of these efforts, adipic acid processes remain still energy consuming. $6,11,15$

In the context of the development of more sustainable oxidation reactions, many aspects of the conditions used and processes involved are increasingly taken into account in order to reduce their impact on the environment. Thus, concerns on energy saving, increase of atom efficiency, use of less harmful compounds or waste minimization have been addressed through studies on the nature of the oxidant. ${ }^{18-21}$ The need to substitute usual oxidants (from $\mathrm{HNO}_{3}$ to $\mathrm{NaIO}_{4}$ in Table 1) was driven by their high environmental impact since they are toxic, corrosive, require high reaction temperatures and lead to the formation of stoichiometric amounts of more or less toxic salts or by-products. ${ }^{22-26}$ Regarding the green chemistry principles, molecular oxygen or ozone are ideal oxidants because of their high active oxygen content and the generation of non-toxic byproducts (Table 1). Nevertheless, in spite of their strong oxidizing potential, oxidative cleavage processes involving $\mathrm{O}_{2}$ and $\mathrm{O}_{3}$ require complex catalysts, specific reaction setups, energy consuming and hazardous conditions. ${ }^{26-31}$ In the past six decades, hydrogen peroxide has been shown to be a prime candidate to develop clean organic oxidations. It is a very attractive oxidant (Table 1 ) due to its $47 \%$ of active oxygen content and its large availability. $\mathrm{H}_{2} \mathrm{O}_{2}$ also constitutes an ideal oxidant for green chemistry as it is non-toxic, releases only water as theoretical by-product and does not usually require temperatures over $100{ }^{\circ} \mathrm{C}$ for oxidations. ${ }^{32}$ In addition, hydrogen peroxide-mediated reactions also benefit from having a zero E-Factor. ${ }^{21}$

Table 1 Oxidants usually used for alkene oxidative cleavage: active oxygen content and by products. ${ }^{27,30}$

\begin{tabular}{ccc}
\hline Oxidant & $\begin{array}{c}\text { Active oxygen } \\
\text { content (\% wt.) }\end{array}$ & By-products \\
\hline $\mathrm{O}_{3}$ & 100 & None or $\mathrm{O}_{2}$ \\
$\mathrm{O}_{2}$ & 100 & None \\
$\mathrm{O}_{2} / \mathrm{Reducer}$ & 50 & $\mathrm{H}_{2} \mathrm{O}$ \\
$\mathrm{H}_{2} \mathrm{O}_{2}$ & 47 & $\mathrm{H} \mathrm{O}$ \\
$\mathrm{HNO}_{3}$ & 25.4 & $\mathrm{NOx}$ \\
$\mathrm{NaOCl}_{\mathrm{CH}_{3} \mathrm{CO}_{3} \mathrm{H}}$ & 21.5 & $\mathrm{NaCl}$ \\
$\mathrm{KMnO}_{4}$ & 21.1 & $\mathrm{CH}_{3} \mathrm{CO}_{2} \mathrm{H}$ \\
$\mathrm{CrO}_{3}$ & 20.2 & $\mathrm{MnO}_{2}$ \\
$\mathrm{KHSO}_{5}$ & 16 & $\mathrm{Cr}(\mathrm{III}) \mathrm{salts}$ \\
$\mathrm{NaIO}_{4}$ & 10.5 & $\mathrm{KHSO}_{4}$ \\
& 7.5 & $\mathrm{NaIO}_{3}$ \\
\hline
\end{tabular}

The current production of hydrogen peroxide is based at $95 \%$ on the anthraquinone auto oxidation process (AO process) allowing a production of 4.5 million ton/year in $2014^{33}$ mainly for bleaching in the pulp and paper industry and the Hydrogen Peroxide Propylene Oxide Process (HPPO). ${ }^{31,33,34}$ One the one hand, $\mathrm{AO}$ process has to face safety and economic issues to make hydrogen peroxide more competitive with usual oxidants. Indeed, with a selling price varying from 700 to 1200 $\$ /$ ton, $\mathrm{H}_{2} \mathrm{O}_{2}$ is 3 to 5 times more expensive $\mathrm{Cl}_{2}$ used for the production of propylene oxide and up to 30 times expensive than pure oxygen. ${ }^{31,33,36}$ The decreasing of $\mathrm{H}_{2} \mathrm{O}_{2}$ cost by developing new routes for its synthesis is thereby a preliminary step to be implemented for its large scale production and replacement of current oxidants. ${ }^{31,35,36}$ Besides, as $\mathrm{H}_{2} \mathrm{O}_{2}$ is subjected to thermal and catalytic decomposition, 
safety care must be applied to implement $\mathrm{H}_{2} \mathrm{O}_{2}$ within the design of oxidation processes. ${ }^{4,32}$ On the other hand, some processes for the production of key compounds, such as propylene oxide reveal the huge potential of hydrogen peroxide thanks to the possibility of using crude $\mathrm{H}_{2} \mathrm{O}_{2}$ resulting from the AO process. ${ }^{31,33}$ Historically, the reaction has long been undertaken with chlorine through epichlorhydrin process (Scheme $3 \mathrm{a}$ )). It has been later improved by combining the heterogeneous titanosilicate catalyst (TS-1) along with hydrogen peroxide allowing a one-step epoxidation (Scheme 3 b)). ${ }^{35,37}$

Since 2008, the HPPO Process has proven its efficiency by allowing the production of up to 300,000 metric ton/year of propylene oxide with $95 \%$ selectivity.

Improvements of the environmental aspects such as wastewater lowering and energy consumption led BASF-Dow Process to be awarded the USEPA Presidential Green Chemistry Challenge in 2010. ${ }^{35,38}$

a) Epichlorhydrin Process

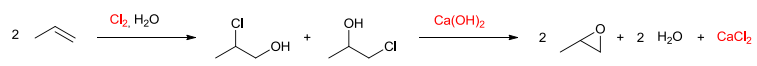

b) HPPO Process

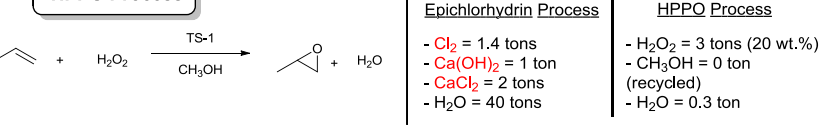

Scheme 3: Industrial processes for propylene oxide production: a) through epichlorhydrin process, b) through Hydrogen Peroxide Propylene Oxide Process
$\left(\mathrm{H}_{2} \mathrm{O}_{2}\right.$ amount calculated from Refs 35 and 38$) ., 40,37,41,39$

Over the past few decades, because of the improved performances of the HPPO process, the use of hydrogen peroxide attracted the interest of researchers for olefin oxidative cleavage. Its growing availability and non-toxicity enabled hydrogen peroxide to be particularly well studied for this reaction. While lots of studies have been carried out and reviews published on the $\mathrm{H}_{2} \mathrm{O}_{2}$-mediated oxidative cleavage of fatty acids ${ }^{29,42,43}$, to the best of our knowledge, no review dealing with the oxidative cleavage of cycloalkenes by hydrogen peroxide have been published to date. ${ }^{44-48}$ Thus, the present contribution aims at bringing a critical view on the development of catalytic systems in combination with hydrogen peroxide for the cleavage of various cycloalkenes. More specifically, a focus on different transition metal-based catalytic systems will be addressed. Also, the current trends on the oxidative cleavage of cyclic olefins with $\mathrm{H}_{2} \mathrm{O}_{2}$ and tungstenbased catalysts will be outlined with a particular emphasis on the catalyst design regarding sustainable development criteria. Finally, the limits of the reaction of the oxidative cleavage of medium-sized rings will be discussed.

\section{Current trends in sustainable oxidative cleavage of cycloalkenes with $\mathrm{H}_{2} \mathrm{O}_{2}$}

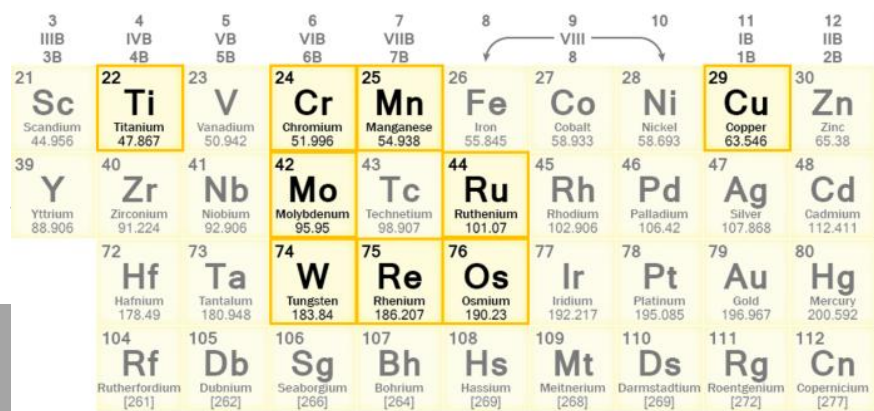

\subsection{Oxidative cleavage with transition metal-based catalysts}

Scheme 4: Transition metal-based catalysts studied for the oxidative cleavage of cycloalkenes with $\mathrm{H}_{2} \mathrm{O}_{2}$ (adapted from Ref 49).

\subsubsection{Copper and osmium-based catalysts}

Among the realm of the catalysts investigated for the cycloalkenes oxidative cleavage, transition metal-based ones are among the most efficient. Indeed, their interaction with hydrogen peroxide produces oxo- and peroxo-complexes, which are very active toward the oxidation of carbon-carbon double bonds.

Hence, the copper complex of tetraazatetradecatetraene proved to be more efficient than $\mathrm{OsO}_{4}$ to convert styrenes to benzaldehyde derivatives in the presence of $\mathrm{H}_{2} \mathrm{O}_{2}{ }^{50,51}$ However, both of them resulted in low oxidative cleavage results. The only efficient osmium-based systems for cycloalkenes oxidative cleavage are based on waste generating Oxone ${ }^{\circledR}\left(\mathrm{KHSO}_{5}, 0.5 \mathrm{KHSO}_{4}, 0.5 \mathrm{~K}_{2} \mathrm{SO}_{4}\right) .{ }^{51}$

\subsubsection{Titanium-based catalysts}

Among the transition-metal based compounds studied for the oxidative cleavage of cycloalkenes, titanium substituted materials were particularly investigated as heterogeneous catalysts. These insoluble modified materials can be recovered at the end of the reaction and their titanium sites present interesting catalytic activity and selectivity. ${ }^{52,53}$ TAPO-5 was the first example of titanium-based catalyst used in the cycloalkene oxidative cleavage. This titanium-incorporated aluminophosphate-framework presents acidic Brønsted sites favouring key steps of the reaction. However, even after $72 \mathrm{~h}$ of reaction with $25 \% \mathrm{H}_{2} \mathrm{O}_{2}$, TAPO-5 allowed the formation of adipic acid in only $30 \%$ yield (Scheme 5 ). ${ }^{54}$ Its low catalytic activity was attributed to both the hydrophilic character of alumino-phosphate structure and the progressive inhibition of the catalyst microporosity by the water formed from $\mathrm{H}_{2} \mathrm{O}_{2} .{ }^{55}$ Similarly, the Ti-MMM titanium-based catalyst has been synthesized from mesoporous silica to study its activity for the cyclohexene cleavage under solvent-free conditions. In spite of its high specific area and enhanced stability, the adipic acid yield never exceed $30 \%$. The authors explained these low results by a partial loss of the mesoporous structure and destruction of the active sites because of reaction medium aggressiveness (Scheme 5). ${ }^{56}$

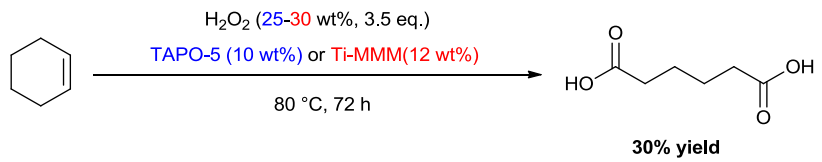

Scheme 5: Oxidative cleavage of cyclohexene with $\mathrm{H}_{2} \mathrm{O}_{2}$ mediated by titaniumsubstituted heterogeneous materials.

The hypothesis of the progressive water poisoning of these catalysts is further supported by the only successful results reported with tert-butyl hydroperoxide (TBHP) as the oxidant. Indeed, with an aluminium and titanium-modified mesoporous silica Ti-AISBA-15, Bonardet et al. performed the oxidative cleavage of cyclohexene in only one day instead of three. 
Adipic acid was produced in $84 \%$ yield, without leaching of titanium species grafted on the silica. ${ }^{57}$

However, as the reaction involves 4 equivalents of TBHP, the development of the technology based on this oxidant appeared not economically viable due to its high cost.

\subsubsection{Chromium-based catalysts}

Based on historical excellent results obtained with the use of $\mathrm{CrO}_{3}$ for double bond oxidative cleavage ${ }^{27}$, chromium has been used for the design of Metal-Organic Frameworks (MOFs). These microporous crystalline materials are three-dimensional structures made up of a metal ions or clusters linked to bi- or multipodal organic linkers. Because of its high valence and coordination ability, chromium has been widely used for designing MOFs displaying the largest pore-sized metal catalysts. ${ }^{58}$ Chromium-based MOFs are used for various applications such as gas adsorption, separation processes and even catalysis due to their high porosity and large surface area. ${ }^{59}$ They present a structure and a microporosity that are comparable to those of zeolites leading to high specific areas. Contrary to zeolites that have 178 known structures, MOFs exhibit a wider variety of shape and size porosity due to their ability to tune metals and organic linkers. ${ }^{59}$ Tangestaninejad and Moghadam et al. described the synthesis of MOF MIL-101 from chromium nitrate and terephthalic acid and its use to catalyse alkene and cycloalkene oxidative cleavage with $\mathrm{H}_{2} \mathrm{O}_{2}$ (Scheme 6). ${ }^{60,61}$ Recently, the same group described the deposition of MIL-101 on magnetic nanoparticles of $\mathrm{Fe}_{3} \mathrm{O}_{4}$ to make the catalyst more easily recovered. ${ }^{62}$ Similar oxidative cleavage results were observed under similar conditions and the deposited catalyst proved its activity after 5 successive runs with yields exceeding $90 \%{ }^{62}$ In both studies, the use of MIL-101 led to high dicarboxylic acid yields but its synthesis requires hazardous conditions. Indeed, it involves dangerous compounds such as hydrofluoric acid and the toxic DMF, severe synthetic conditions and lengthy overall purification. ${ }^{60,61}$ A large excess of hydrogen peroxide is also necessary to reach high dicarboxylic acids yields. Moreover, the use of chromium compounds is no longer favoured in the industry due to the high toxicity of $\mathrm{Cr}(\mathrm{VI})$ salts used or generated during the reaction. $^{63}$

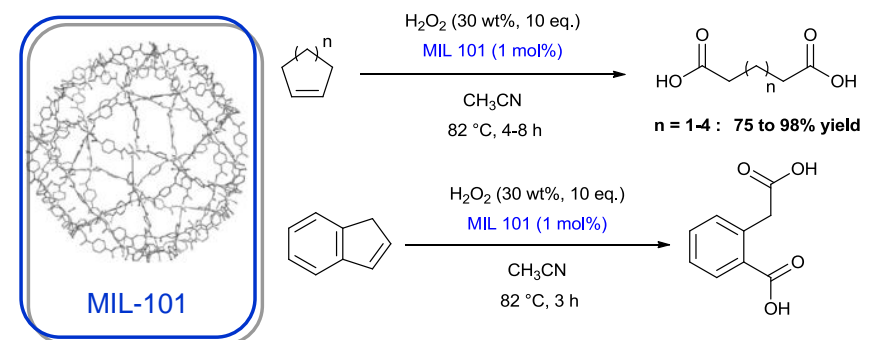

Scheme 6: Schematic representation of MIL 101 (left, reproduced with the permission of Ref 57 ) and oxidative cleavage of various cycloalkenes with $\mathrm{H}_{2} \mathrm{O}_{2}$
mediated by chromium based Metal-Organic Framework MIL-101 (right).

\subsubsection{Rhenium-based catalysts}

One of the oldest system patented for the oxidative cleavage of cycloalkenes with $\mathrm{H}_{2} \mathrm{O}_{2}$ goes back to the 70's and reports the use of rhenium-based catalyst. More specifically, a patent from Dupont describes the use of $\operatorname{Re}_{2} \mathrm{O}_{7}$ as the catalyst for the cleavage of cyclododecene at $120^{\circ} \mathrm{C}$ with acetic acid, yielding to only $30 \%$ of dicarboxylic acid. ${ }^{64}$ Next, MethylTriOxorhenium (MTO) and related organo-rhenium compounds were well studied for various oxidation reactions. ${ }^{65,66}$ Recently, the combination of quaternary ammonium perrhenates with ionic liquids have been reported for the cyclooctene oxidative cleavage. Advantageously, this system offers the possibility to recover the amphiphilic active catalyst at the end of the reaction. ${ }^{67}$ Then, using $[\mathrm{HMIm}]\left[\mathrm{HSO}_{4}\right]$ loaded with $5 \%$ of catalyst, $75 \%$ yield of suberic acid have been obtained after $6 \mathrm{~h}$ at $80{ }^{\circ} \mathrm{C}$ in the presence of 5 eq. of $\mathrm{H}_{2} \mathrm{O}_{2}$ (Scheme 7). ${ }^{67}$ It also afforded $88 \%$ yield of adipic acid from cyclohexene. Despite their high activity, these systems present some drawbacks, especially their high cost and ionic liquid degradation, to be

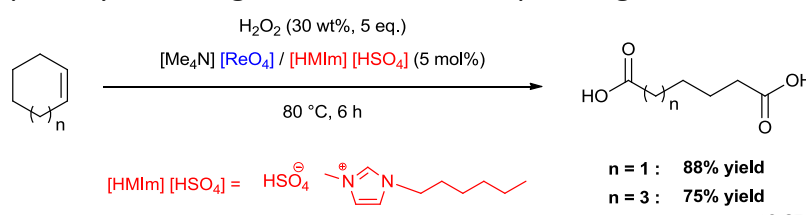

competitive with other transition metal-based catalysts. $\mathbf{4 0 , 6 7 , 6 8}$

Scheme 7: Oxidative cleavage of cyclooctene and cyclohexene mediated by perrhenate-containing composite ionic liquid.

\subsubsection{Ruthenium-based catalysts}

Che et al. investigated the use of a homogeneous rutheniumbased catalyst to perform the cleavage of various cycloalkenes in a tert-butanol/water mixture. In the presence of only 1 mol\% of Ru-Me $\mathrm{M}_{3}$ tacn complex and 5 eq. of $35 \% \mathrm{H}_{2} \mathrm{O}_{2}$, linear and branched dicarboxylic acids were synthesized with excellent yields in only $3 \mathrm{~h}$ of reaction (Scheme 8$).{ }^{69}$ The scaling-up to $1 \mathrm{~mol}$ for the oxidative cleavage of cyclohexene and cyclooctene allowed the production of the corresponding adipic and suberic acids in 85 and $91 \%$ yields respectively, after $12 \mathrm{~h}$ of reaction. Nevertheless, ruthenium-based complexes still have to face important drawbacks before being integrated into sustainable oxidation systems. Especially, ruthenium is the sixth rarest metal in earth crust due to its low abundance making its complexes and catalysts very expensive..$^{29,40,68,70}$ In addition, ruthenium is involved in long and tedious pathways for the synthesis of the catalytic complexes ${ }^{69}$ and harmful oxidants are required for the recycling of ruthenium-based catalysts. $^{71}$

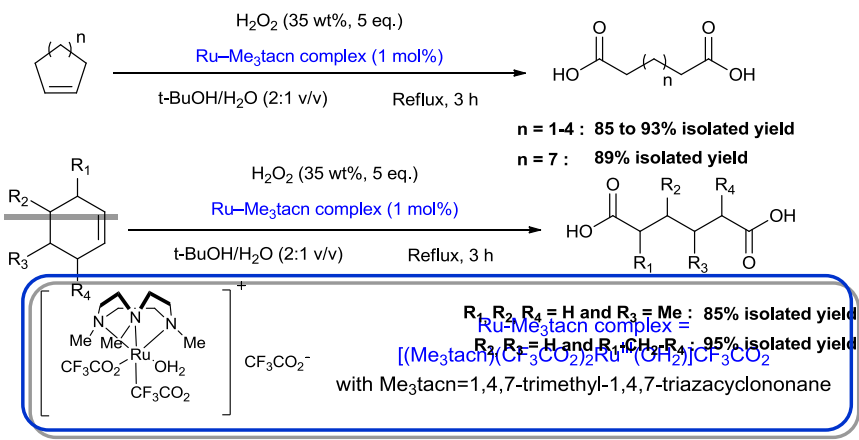


Scheme 8: Oxidative cleavage of various cycloalkenes with $\mathrm{H}_{2} \mathrm{O}_{2}$ mediated by $\mathrm{Ru}$ $\mathrm{Me}_{3} \mathrm{tacn}$ complex.

\subsubsection{Manganese-based catalysts}

Long-time known for the oxidation of alkenes with $\mathrm{H}_{2} \mathrm{O}_{2}$ metallocomplexes, manganese catalysts have been rarely described for the alkene oxidative cleavage. An exception to this is the Y-zeolite-encapsuled manganese bipyridyl complex $\left[\mathrm{c}-\mathrm{Mn}(\mathrm{bpy})_{2}\right]^{2+}-\mathrm{Y} \quad\left(\right.$ bpy $\left.=\left(\mathrm{C}_{6} \mathrm{H}_{4} \mathrm{~N}\right)_{2}\right)$. Indeed, this intrazeolite manganese complex proved its efficiency at $20{ }^{\circ} \mathrm{C}$ by reaching dicarboxylic acids yields over $80 \%$ in $40 \mathrm{~h}$ from cyclohexene and cyclododecene (Scheme 9). ${ }^{\mathbf{7 2}}$ Appart from these results, very few studies relate the $\mathrm{H}_{2} \mathrm{O}_{2}$-mediated oxidative cleavage with manganese species. Recently, a promising manganesebased ecocatalyst "Eco-Mn" was synthesized from $\mathrm{Mn}$ hyperaccumulating plants; unfortunately, using this catalyst, the oxidative cleavage of styrene stops at the aldehyde intermediate stage. ${ }^{73}$

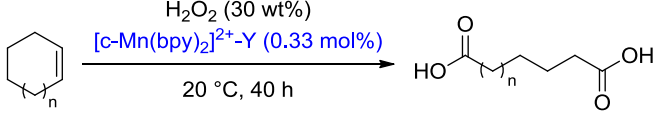

$$
\begin{aligned}
& \mathrm{n}=1: \quad 80 \% \text { yield } \\
& \mathbf{n = 7}: \quad 84 \% \text { yield }
\end{aligned}
$$
Scheme 9: Oxidative cleavage of cyclohexene with $\mathrm{H}_{2} \mathrm{O}_{2}$ mediated by [c-
$\left.\mathrm{Mn}(\mathrm{bpy})_{2}\right]^{2+}-\mathrm{Y}^{.2}$

\subsubsection{Molybdenum-based catalysts}

Among the transition-metal based catalysts described for $\mathrm{H}_{2} \mathrm{O}_{2}$-mediated oxidative cleavage, molybdenum complexes have been very well studied along with their tungsten analogues. Their physico-chemical properties allowed them to be used for various oxidation reactions such as alkene epoxidation, alcohol, amine and sulfide oxidation, and oxidative cleavage. They were also studied for the characterization of active peroxocompounds formed during reactions with hydrogen peroxide. ${ }^{74-76}$ Only few studies highlight benefits of using molybdenum compounds for adipic acid synthesis. For instance, 12-molybdophosphoric acid $\left(\mathrm{H}_{3} \mathrm{PMo}_{12} \mathrm{O}_{40}\right)$ supported on aluminum oxide showed a higher efficiency than other catalysts deposited on various metal oxides $\left(\mathrm{H}_{3} \mathrm{PW}_{12} \mathrm{O}_{40}, \mathrm{H}_{3} \mathrm{PW}_{6} \mathrm{Mo}_{6} \mathrm{O}_{40}\right.$ deposited on aluminum, magnesium or zinc oxides) for the oxidative cleavage of cyclohexene. Despite very good performances under heterogeneous conditions, the reaction required $24 \mathrm{~h}$ in $t$ $\mathrm{BuOH}$ in the presence of $70 \% \mathrm{H}_{2} \mathrm{O}_{2}$ affording adipic acid in $90 \%$ yield. ${ }^{71}$ Besides, among the few details given on the prepared catalysts, recovery runs showed a loss of efficiency after the $4^{\text {th }}$ reuse. Molybdenum catalysts were also studied under heteropolyanionic form. Among heteropolysalts tested by Alcañiz-Monge et al., calcined $\mathrm{CsPMo}_{12} \mathrm{O}_{40}$ showed the highest catalytic activity thanks to the peroxoanions formed at the surface of catalyst nanoparticles. ${ }^{77}$ XRD and UV-Vis analyses highlighted the heterogeneous nature and stability of these catalysts. Addition of acetic acid to the system was also described as essential to limit $\mathrm{H}_{2} \mathrm{O}_{2}$ decomposition. Under these heterogeneous conditions, cyclohexene oxidative cleavage thus resulted in $80 \%$ yield of adipic acid (Scheme 10 ).

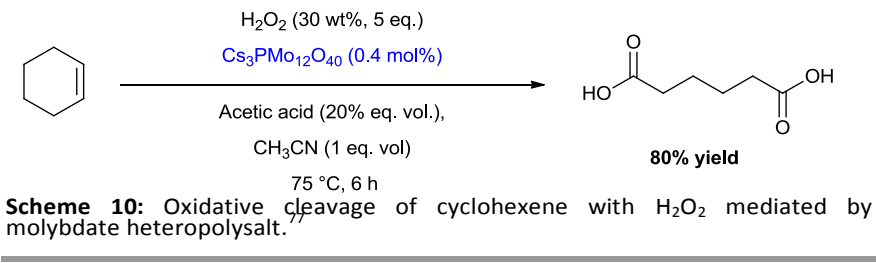

Study of the reaction under biphasic conditions was carried out by Buonomena et al.. The cyclohexene and the oxidizing media were flowed separately into an inert polymeric membrane reactor. ${ }^{78}$ Ammonium tetramolybdate $\left(\mathrm{NH}_{4}\right)_{6} \mathrm{Mo}_{7} \mathrm{O}_{24}$ was chosen as the homogeneous catalyst since it is $30 \%$ cheaper than usual $\mathrm{Na}_{2} \mathrm{WO}_{4}$. Separative membranes were particularly efficient to keep a stable interface during reactant flowing and to separate adipic acid during its formation. Under continuous flow conditions, the best yield of $90 \%$ was obtained after $6 \mathrm{~h}$ of reaction at $90{ }^{\circ} \mathrm{C}$ with succinic acid as molybdenum's ligand.

In spite of similar reactivity, molybdenum-based complexes seldom showed higher performances to tungsten-based ones. Indeed, the literature on $\mathrm{H}_{2} \mathrm{O}_{2}$-mediated cycloalkene oxidative cleavage describes the almost exclusive use of tungsten-based catalysts because of their numerous advantages compared to other transition metal-based catalysts.

\subsection{Tungsten-catalysed oxidative cleavage}

Over the past 30 years, studies dedicated to the development of greener conditions for the oxidative cleavage of cycloalkenes with $\mathrm{H}_{2} \mathrm{O}_{2}$ mainly dealt with the use of tungstenbased catalysts. Indeed, the latter benefit from the numerous advantages of tungsten ${ }^{79}$ such as its non-toxicity ${ }^{80,81}$ and its availability. ${ }^{40,82}$ Furthermore, this transition metal is very active toward hydrogen peroxide affording active peroxocomplexes. ${ }^{83-85}$ To determine the critical parameters of the reaction, several reaction mechanisms involving tungstenbased catalysts have been suggested both on experimental observations and theoretical considerations.

\subsubsection{Mechanistic and experimental considerations}

Common characteristics on reaction conditions have been highlighted throughout the studies made on the cycloalkene oxidative cleavage with tungsten-based catalysts. More specifically, the need of acidic conditions, of a minimum amount of 4 equivalents of $\mathrm{H}_{2} \mathrm{O}_{2}$ and of a minimum temperature of $80{ }^{\circ} \mathrm{C}$ are the necessary conditions leading to high oxidative cleavage yields (70-95\%). Besides, most studies highlight the presence of 3 main by-products along with dicarboxylic acids: cycloalkenes derived epoxides, 1,2-diols and $\alpha$-hydroxyketones. ${ }^{86-90}$ Previous experimental observations and considerations on hydrogen peroxide activity suggested that the reaction occurs via a multi-step mechanism involving 
at least epoxide, diol and $\alpha$-hydroxy-ketone intermediates (Scheme 11, compounds 2, 3, 4).

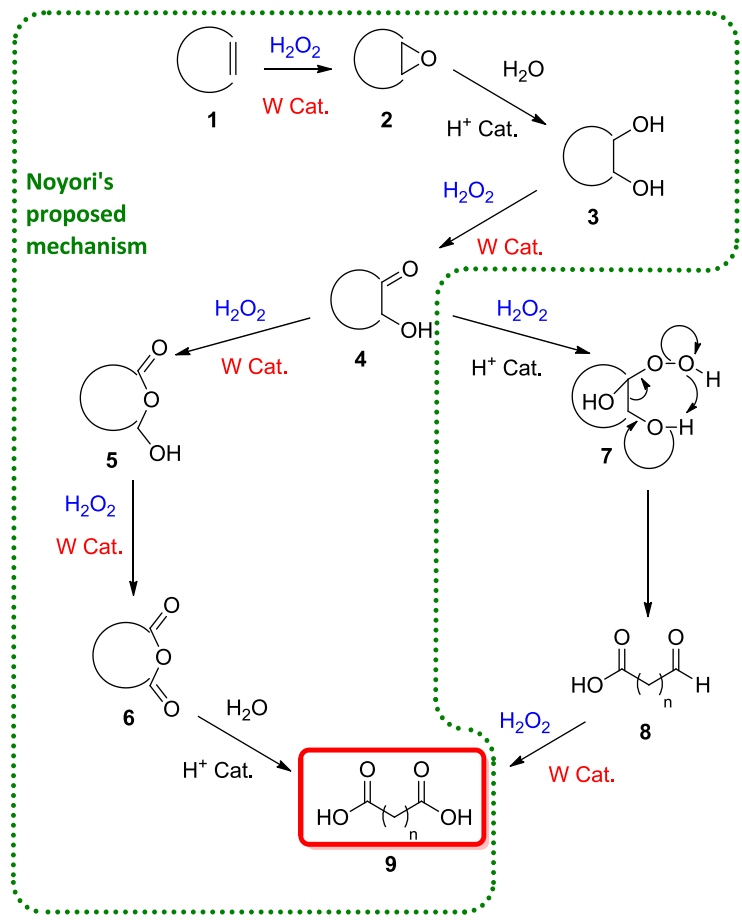

Scheme 11: Hypothetic mechanism for the $8 x i d a t i v e$ cleavage of cycloalkenes with $\mathrm{H}_{2} \mathrm{O}_{2}$ and a tungsten-based catalyst.

One of the most cited mechanism to rationalize the hydrogen peroxide-mediated oxidative cleavage of cycloalkenes was proposed by Noyori et al. (Scheme 11).$^{13}$ In this scheme, the oxidative cleavage involves 6 distinct oxidation and hydrolysis steps: alkene epoxidation, epoxide hydrolysis, $1^{\text {st }}$ alcohol oxidation, Baeyer-Villiger reaction, $2^{\text {nd }}$ alcohol oxidation and cyclic anhydride hydrolysis. This mechanism is a little different from the one known for the oxidative cleavage of linear olefins involving a $\mathrm{C}-\mathrm{C}$ bond cleavage of 1,2-diol intermediate into two aldehydes that are further oxidized into carboxylic acids. ${ }^{29,30,42}$ Even if the formation of intermediates $\mathbf{2}$ to $\mathbf{4}$ have been well explained, up to date, no studies highlights the presence of the Baeyer-Villiger ring enlargement during the oxidative cleavage. Only indirect studies propose the presence of products $\mathbf{5}$ and $\mathbf{6}$ in the mechanism. ${ }^{91-93}$

Additional contributions from Venturello et al. allowed considering other intermediates in this multi-step reaction. In fact, the formation of hydroperoxyalcohol 7 arose from the detection of the mono-aldehyde $\mathbf{8}^{89}$ Hypothesis of oxidation of the latter compound to the dicarboxylic acid has been then supported by further studies on aldehyde oxidation. ${ }^{94,95}$ Combinations of Noyori's and Venturello's mechanisms have also been suggested to complete the reaction pathway. In fact, a study on the oxidative cleavage of 1,2-cyclohexanediol and its derivatives carried out by Fujitani et al. led to consider the presence of both Venturello's hydroperoxy-alcohol $\mathbf{7}$ and semialdehyde 8 and Noyori's Baeyer-Villiger product 5 . $^{96}$
In spite of these numerous propositions, no complete mechanism has been established yet for explaining the transformation of the hydroxy-ketone $\mathbf{4}$ to the final dicarboxylic acid. However, these different studies evidenced some other common points such as the absence of possible 1,2-dione through hydroxy-ketone oxidation and the identification of epoxide hydrolysis as the rate determining step of the reaction. ${ }^{13,89,96}$

Among the various mechanisms reported in the literature, all of them require 2 key experimental conditions, which are:

(i) The use of a minimum of 4 equivalents of $\mathrm{H}_{2} \mathrm{O}_{2}$. Indeed, this minimal amount required is supported by the four distinct oxidation steps taking place from the cycloolefin to the diacid production. Experimentally, 4.4 equivalents are commonly used to ensure a sufficient amount of oxidant that could be thermally or catalytically decomposed.

(ii) The use of an acidic source, since best oxidative cleavage yields were obtained in the $0-3 \mathrm{pH}$ range. These very acidic conditions are essential to form the active catalyst, ${ }^{88,97,87,98}$ perform the acidic steps of the reaction ${ }^{13,90}$ but also to prevent $\mathrm{H}_{2} \mathrm{O}_{2}$ from thermal and catalytic decomposition. ${ }^{4,32,33}$ Indeed, at $\mathrm{pH}<3$ the disproportionation reaction of $\mathrm{H}_{2} \mathrm{O}_{2}$ into $\mathrm{H}_{2} \mathrm{O}$ (Eq. 1) and $\mathrm{O}_{2}$ (Eq. 2) is slow. In addition, according to the $\mathrm{E}_{\mathrm{h}}-\mathrm{pH}$ equations of hydrogen peroxide, low $\mathrm{pH}$ values also increase the $\mathrm{H}_{2} \mathrm{O}_{2}$ redox potential (Eq. 3. and 4). ${ }^{99}$

$\mathrm{H}_{2} \mathrm{O}_{2}+2 \mathrm{H}^{+}+2 e^{-} \rightarrow 2 \mathrm{H}_{2} \mathrm{O}$
$\mathrm{H}_{2} \mathrm{O}_{2} \rightarrow \mathrm{O}_{2}+2 \mathrm{H}^{+}+2 e^{-}$

$E_{h}=1.776-0.0591 p H+0,0295 \log \left(H_{2} O_{2}\right)$

$E_{h}=0.682-0.0591 p H+0,0295 \log \frac{\mathrm{PO}_{2}}{\left(\mathrm{H}_{2} \mathrm{O}_{2}\right)}$

Moreover, the action of hydrogen peroxide on tungstate species leads to water soluble complexes which are stabilized under acidic conditions. Firstly described by Pourbaix as pertungstic acid $\mathrm{H}_{2} \mathrm{WO}_{5} \cdot \mathrm{H}_{2} \mathrm{O}_{2}{ }^{99}$, more recent studies by Griffith et al. revealed that these complexes are actually polyperoxotungstates that are formed under $\mathrm{pH}<3$. $^{75,85,100}$

Hence, a large variety of heterogeneous and homogeneous tungsten-based catalysts have been studied to improve the environmental performances of cycloalkenes oxidative cleavage in the presence of aqueous $\mathrm{H}_{2} \mathrm{O}_{2}$.

\subsubsection{Tungsten-based heterogeneous catalysts}

Tungsten-based heterogeneous materials have been investigated due to the low environmental impact and high activity of peroxo-tungsten compounds. Their catalytic action as heteropolyanions towards various liquid organic reactions have even been comprehensively reviewed recently. ${ }^{101}$ Generally, heterogeneous tungsten-based systems are based on inorganic frameworks resistant to strong oxidizing conditions and allowing to reuse the catalytic system over 
multiple runs. First catalysts designed for the reaction were mesoporous silica-based materials.

First catalytic oxidative cleavage was reported with SBA-15type catalyst, comprising a mesoporous silica-based structure containing 0.06 wt\% oxotungsten sites.

However, the highest adipic acid production was observed after $30 \mathrm{~h}$ reaction with $45 \%$ yield thanks to a catalyst reused from a previous run. ${ }^{102}$ Few years later, the outcome of the reaction was improved with a similar mesoporous silica displaying surface-integrated oxo-tungsten sites. Holmberg et al. reported the use of a modified silica fully characterized. This catalyst showed better performances than the previously described one. Indeed, adipic acid was synthesized in $95 \%$ yield after $24 \mathrm{~h}$ reaction at $80{ }^{\circ} \mathrm{C}$ under solvent-free conditions in the presence of $\mathrm{H}_{2} \mathrm{SO}_{4}{ }^{103} \mathrm{It}$ is worth noting that the surfacemodified materials led to larger amounts of dicarboxylic acid than the reactions that used a mixture of silica and soluble tungsten catalyst. Unfortunately, despite the recyclability of the catalyst and a shorter reaction time, a progressive contamination of the catalyst prevented additional runs. Moreover, the hydrophilic nature of these mesoporous materials often constitutes a limitation for the oxidation of lipophilic substrates under biphasic conditions. Finally, the use of 2 weight equivalents of catalyst compared to cyclohexene, makes the process non-economically-viable.

Modified organic-inorganic hybrid silica have been then designed to enhance the solubility of ionic tungsten species. ${ }^{104}$ These heterogeneous materials are composed of a silica matrix covalently functionalized with terminal alkyl ammonium that can interact with soluble tungstate ions (Scheme 12). Such structure combines the advantages of both heterogeneous and homogeneous catalysis. Indeed, the organic tails enhance the solubility of the catalyst in lipophilic substrates while the inorganic shell ensures its recovery. Thus, alkyl ammonium groups play the role of quasi-homogeneous phase transfer catalysts due to the amphiphilic nature of the organic chain they contain. The first use of these particular materials was described by Hashemi et al.. In their study, the catalyst was prepared from a silica gel functionalized by sodium tungstate and 2-[2-(3-trimethoxysilylpropylamino) ethylamino] ethylamine. ${ }^{104}$ By mixing $43 \mathrm{wt} \%$ of the catalyst, $5.5 \mathrm{~mol} \%$ of $p$ toluenesulfonic acid and 4.4 equivalents of $30 \%$ aqueous $\mathrm{H}_{2} \mathrm{O}_{2}$, cyclohexene was transformed to the corresponding diacid in $89 \%$ yield, after $20 \mathrm{~h}$ of reaction. This kind of organic-inorganic structure has also been studied for the design of hybrid Zr-SBA 15 mesoporous silica. The synergy of the zirconium ions with the SBA-15 structure is described as particularly significant to form strong bonds with amino-based molecules. Active hybrid catalyst has been functionalized by PentaEthyleneHexAmine (PEHA) and pre-synthesized $\mathrm{H}_{3} \mathrm{PW}_{4} \mathrm{O}_{24}{ }^{105}$ This semihomogeneous catalyst led to adipic acid with $89 \%$ yield in only $8 \mathrm{~h}$ with a slightly higher amount of $\mathrm{H}_{2} \mathrm{O}_{2}(30 \%)$. Both of these materials can be recycled and reused over 4 cycles, allowing to reach a dicarboxylic acid yield above $80 \%$. Nevertheless, these specific materials suffer from being involved in very long and energy consuming syntheses. Indeed at least three reaction steps are required to form these catalysts with reaction times ranging from $4 \mathrm{~h}$ to $24 \mathrm{~h}$ at temperatures exceeding $90{ }^{\circ} \mathrm{C}$. Besides, harmful compounds such as concentrated $\mathrm{HCl}, \mathrm{H}_{3} \mathrm{PO}_{4}$ or $\mathrm{CF}_{3} \mathrm{SO}_{3} \mathrm{H}$ and toxic solvents such as $\mathrm{Et}_{2} \mathrm{O}, \mathrm{CH}_{2} \mathrm{Cl}_{2}$ or toluene are usually involved. ${ }^{104,105}$
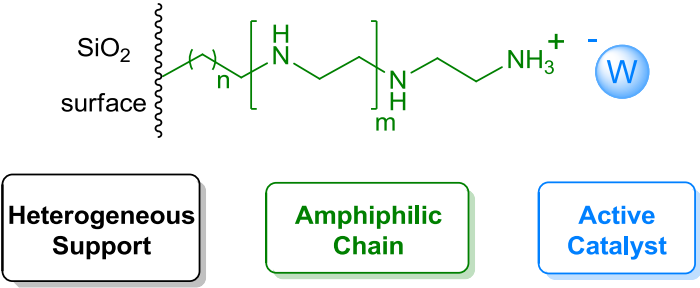

Scheme 12: Schematic representation of organic-inorganic hybrid silica material.

Recently, the idea of performing reactions under homogeneous catalysis conditions using a heterogeneous catalyst has been reported under a "catch and release" catalytic cycle. Here, a supported catalyst made up of $\mathrm{WO}_{3} / \mathrm{Zn}-$ $\mathrm{SnO}_{2}$ is described for the oxidative cleavage of cyclohexenes leading to a minimum of $75 \%$ yield over 10 reaction cycles. ${ }^{106}$ Under these conditions, tungsten catalyst is released into the media as soluble peroxotungstates and catalyses the reaction while hydrogen peroxide is present. As soon as $\mathrm{H}_{2} \mathrm{O}_{2}$ is completely consumed, tungstates are "caught" back onto the heterogeneous support under the $\mathrm{WO}_{3}$ form and can be reused over multiple cycles. This example combining the advantages of homogeneous and heterogeneous catalysis illustrates a promising system for sustainable organic synthesis. Nevertheless, solvents are still needed for the syntheses of both catalyst and adipic acid and long reaction times make these processes non-productive and economically unattractive.

\subsubsection{Heteropolyacids and polyoxometalates for oxidative cleavage}

As heterogeneous systems require non-environmentallyfriendly synthetic pathways and long reaction times to perform oxidative cleavages, water-soluble forms of tungsten catalysts have been also investigated. Among the developed homogeneous catalysts, polyoxometalates, known as POM's, have been well studied because of their multiple features allowing to perform the different stages of oxidative cleavage. These catalysts are composed of three dimensional molecular structures constituted by multiple early transition metal atoms bridged to each other via oxygen atoms (Scheme 13). ${ }^{107,108}$ In combination with hydrogen peroxide, these complexes display interesting features such as a strong oxidizing ability, a high thermal stability and a wide range of physico-chemical properties conferred by their tunable features..$^{31,40,84,109}$ Most of the time, these hydrophilic anionic complexes are paired 
with lipophilic quaternary ammoniums or pyridiniums-type to react with alkenes in organic medium.
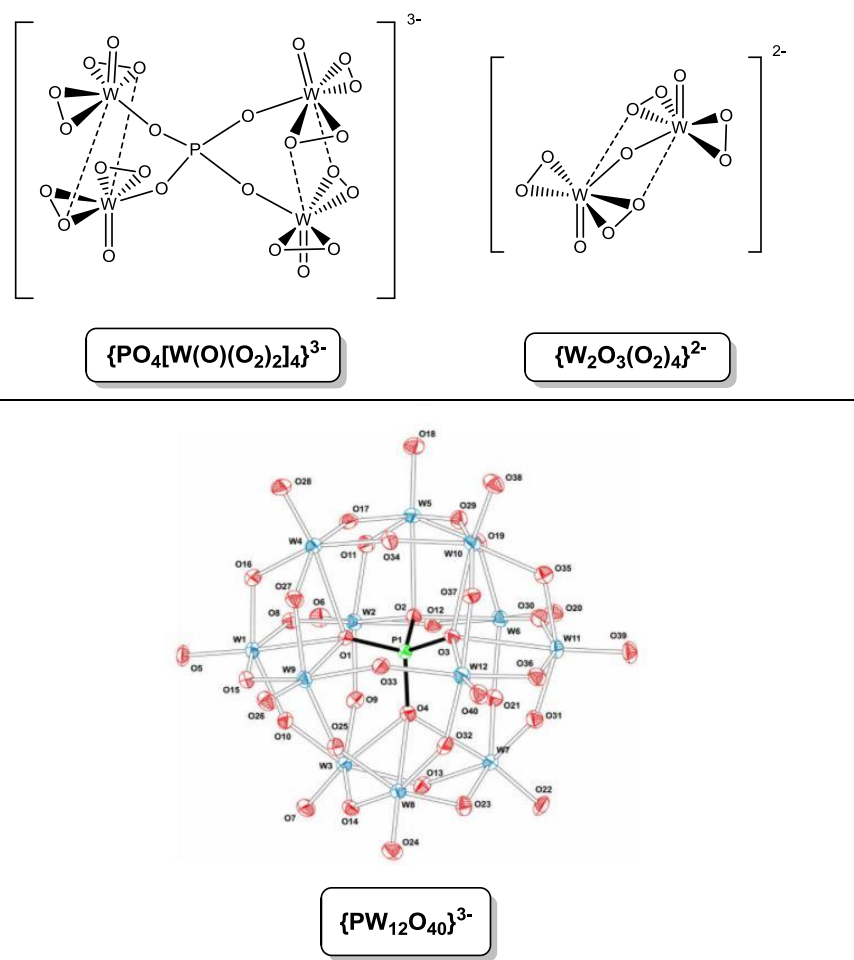

Scheme 13: Structures of some POM used for the oxidative cleavage $e_{85}, f_{0}, \mathrm{f}=\mathrm{C}$ double bonds with $\mathrm{H}_{2} \mathrm{O}_{2}$ (upward, representations adapted from Refs with the permission of the International Union of Crystallography).

POM-based complexes can be composed of only one type of early transition metal and are so-called isopolyanions. Among the publications describing $\mathrm{H}_{2} \mathrm{O}_{2}$-mediated oxidative cleavage of $\mathrm{C}=\mathrm{C}$ double bonds, very few studies relate on the preparation and isolation of polyoxotungstates as oxidation catalysts. To the best of our knowledge, such complexes were only described by Li et al. ${ }^{113}$ who succeeded in the synthesis and characterization of surfactant-type polyoxometalates constituted of a dimeric anion $\left[\mathrm{M}_{2} \mathrm{O}_{3}\left(\mathrm{O}_{2}\right)_{4}\right]^{2-}(\mathrm{M}=\mathrm{W}$ and $\mathrm{Mo})$ and a cationic long lipophilic chain possessing a phase transfer function as the catalyst. Peroxotungsten anion-containing catalysts were particularly efficient, leading to a very good $78 \%$ yield for the cyclohexene oxidative cleavage (Table 2, Entries 1 and 2). Indeed, tungsten-based polyoxometalates led to better results than their molybdenum counterparts due to their ability to preserve $\mathrm{H}_{2} \mathrm{O}_{2}$ from decomposition. ${ }^{113}$ However, they require at least $20 \mathrm{~h}$ reaction times to perform the reaction.

Among the literature describing the catalytic oxidations with POMs, heteropolyanions have been most studied because of their high stability and activity. These complexes are constituted of $\mathrm{p}$ or d block "heteroatoms" in addition to metal and oxide ions. Most common tungsten-based POMs used for $\mathrm{H}_{2} \mathrm{O}_{2}$-mediated oxidations are the ones with so-called "Keggintype" structure (Fig. 1). ${ }^{40,109,114}$ Within the field of oxidations with heteropolyoxometallates, Venturello and Ishii carried out extensive researches to synthesize, characterize and use quaternary ammonium heteropolyoxotungstates, especially for olefin epoxidations. ${ }^{86,97,110,115}$

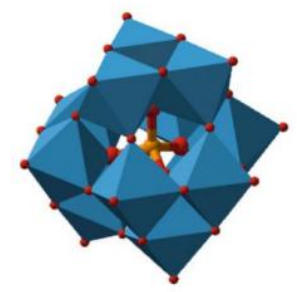

Fig. 1: Three dimensional structure of Keggin-Type polyoxometalate. The genera formula is $\mathrm{XM}_{12} \mathrm{O}_{40}$ where $\mathrm{X}$ is typically $\mathrm{P}$ or $\mathrm{S}$ (orange atom), $\mathrm{M}$ is $\mathrm{Mo}$ or $\mathrm{W}$ (non visible atoms at the center of blue octahedras) and $x$ the metal oxidation state (reproduced from the permission of Ref 40).

Preliminary studies made for the design of tungsten-based complexes were undertaken in the 80 's by Venturello et al.. The group described the combination of $\mathrm{Na}_{2} \mathrm{WO}_{4}$ as the tungsten source, $\mathrm{H}_{3} \mathrm{PO}_{4}$ and a Phase Transfer Catalyst (PTC) in 1,2-dichloroethane to convert various terminal alkenes into their epoxide derivatives. 70 to $90 \%$ yields were reported on the basis of the $\mathrm{H}_{2} \mathrm{O}_{2}$ charged but these results did not exceed $52 \%$ when calculated on olefin concentration, as an excess of alkene is required to perform the reaction (Scheme 14). ${ }^{97}$ Advanced analyses on the active species succeeded in the first complete isolation and characterization of a polyperoxometalate complex known today as the "IshiiVenturello's complex". It is composed of the active anion $\left\{\mathrm{PO}_{4}\left[\mathrm{~W}(\mathrm{O})\left(\mathrm{O}_{2}\right)_{2}\right]_{4}\right\}^{3-}$ coupled with its quaternary ammonium moiety (Scheme 14). ${ }^{110}$

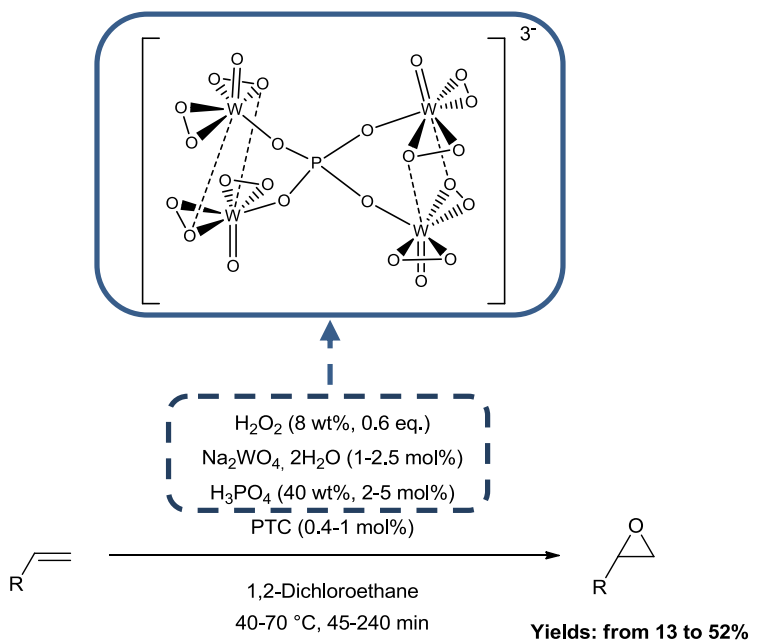

Scheme 14: Epoxidation of terminal alkenes mediated by “Ishii-Venturello's complex"

From the discovery of Venturello's active catalyst $\left\{\mathrm{PO}_{4}\left[\mathrm{~W}(\mathrm{O})\left(\mathrm{O}_{2}\right)_{2}\right]_{4}\right\}^{3-}$, many studies were undertaken to identify the mono- and polynuclear species formed during the oxidation of the catalyst by $\mathrm{H}_{2} \mathrm{O}_{2}{ }^{75,85,98,111}$ Venturello's system was later improved for olefin epoxidation ${ }^{116}$ while progressively considering environmental aspects of the reaction ${ }^{117}$ transposed to olefin oxidative cleavage. ${ }^{90}$ 
The first successful results for the oxidative cleavage of cycloalkenes with $\mathrm{H}_{2} \mathrm{O}_{2}$ and PTC have been reported by Venturello.

In the corresponding patent, ${ }^{118}$ the cleavage of cyclohexene is performed with $35 \% \mathrm{H}_{2} \mathrm{O}_{2}$ and a complex made up of lipophilic quaternary ammonium and tungstate peroxo-complex $\mathrm{PW}_{4} \mathrm{O}_{22}{ }^{3-}$. This catalyst afforded $99 \%$ pure adipic acid with $71 \%$ yield after $16 \mathrm{~h}$ of reaction in dichloroethane. (Table 2, Entry 3). Next, Ishii succeeded in replacing the chlorinated toxic solvent by $t$-BuOH while using another POM-based catalyst. Indeed, a new catalyst, the tris(cetylpyridinium)tungstophosphate, was obtained from the reaction between 12-tungstophosphoric acid $\left(\mathrm{H}_{3} \mathrm{PW}_{12} \mathrm{O}_{40}\right)$ and cetylpyridinium chloride $\left(\left[\pi-\mathrm{C}_{5} \mathrm{H}_{5} \mathrm{~N}\left(\mathrm{C}_{16} \mathrm{H}_{33}\right)\right]^{+} \quad \mathrm{Cl}^{-}\right)$. Unfortunately, the $24 \mathrm{~h}$ of reaction required to reach dicarboxylic acid yields from $66 \%$ to $90 \%$ makes this reaction uncompetitive (Table 2, Entries 4 to 6). ${ }^{86}$ Also, peroxotungstophosphates with different oxidation states and associated with cetylpyridinium cation were synthesized in order to study their activity. For instance, Ishii's previous conditions were adapted by Dai et al. to perform the solventless oxidative cleavage of cyclopentene in the presence of $\mathrm{PW}_{12} \mathrm{O}_{40}{ }^{3-}$ in only $8 \mathrm{~h}$. Through a progressive and controlled increase of the temperature of the medium and the use of a more concentrated $\mathrm{H}_{2} \mathrm{O}_{2}$ solution, the yield was improved up to $86 \%$ (Table 2, Entry 7). ${ }^{119}$ Tungstophosphate anion $\mathrm{PW}_{12} \mathrm{O}_{40}{ }^{3-}$ was also oxidized to form another heteropolyoxotungstate PTC $\left[\pi-\mathrm{C}_{5} \mathrm{H}_{5} \mathrm{~N}\left(\mathrm{C}_{16} \mathrm{H}_{33}\right)\right]_{3} \quad \mathrm{PO}_{4}\left[\mathrm{WO}_{3}\right]_{4}$. While studying their mode of action in the oxidative cleavage of 1,2-cyclopentanediol, yields as high as before were also observed for the cleavage of cyclopentene and cyclohexene under similar conditions (Table 2, Entries 8 and 9). ${ }^{\mathbf{1 2 0}}$ Besides, both of these catalysts are particularly interesting as they are no longer soluble in the media at the end of the reaction and can be easily recovered. ${ }^{119,120}$ It should be noted that in these works, 3.3 equivalents of 50 wt\% $\mathrm{H}_{2} \mathrm{O}_{2}$ have been used (contrary to the usual 4 equivalents) leading to the formation of the expected dicarboxylic acids.

Among the studied heteropolyoxotungstates, the ones based on the "Ishii-Venturello"'s complex $\left\{\mathrm{PO}_{4}\left[\mathrm{~W}(\mathrm{O})\left(\mathrm{O}_{2}\right)_{2}\right]_{4}\right\}^{3-}$ are still the most active for the cycloalkene oxidative cleavage. This catalyst has been synthesized by Pai et al. ${ }^{121}$ from $\mathrm{H}_{2} \mathrm{WO}_{4}$, $\mathrm{H}_{3} \mathrm{PO}_{4}, \mathrm{H}_{2} \mathrm{O}_{2}$ and Aliquat $336^{\circledR}$, an onium salt made up of

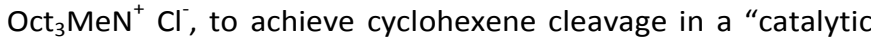
duck reactor". In the presence of a lower amount of hydrogen peroxide than usual, i.e. 2 eq. instead of 4.4 eq., and a shorter time of reaction, i.e. $3 \mathrm{~h}$ instead of $24 \mathrm{~h}$, the olefin was not fully converted but yielded in $72 \%$ of adipic acid. (Table 2 , Entry 10). To date, the conditions disclosed by Venturello for the oxidative cleavage of various olefins by the same catalyst are still the most promising. Indeed, the group described the use of $\left[\left(\mathrm{C}_{8} \mathrm{H}_{17}\right)_{3} \mathrm{NCH}_{3}\right]_{3} \quad \mathrm{PO}_{4}\left[\mathrm{~W}(\mathrm{O})\left(\mathrm{O}_{2}\right)_{2}\right]_{4}$ and proved that optimization of $\mathrm{H}_{2} \mathrm{O}_{2}$ addition into the media led to enhanced results through a better temperature control. ${ }^{90}$ Thus, glutaric and adipic acid were isolated with yields above $80 \%$ under biphasic conditions in less than $7 \mathrm{~h}$ (Table 2, Entries 11 to 14).

As a conclusion, surfactant-type POMs have been particularly studied due to the possibility to select both anion and cation moieties, in order to adjust the solubility and the activity of the catalyst. Nevertheless, among the above cited studies, only very few papers describe the recyclability of such complexes. For instance, only Dai et al. achieved to reuse the catalyst [ $\pi$ $\left.\mathrm{C}_{5} \mathrm{H}_{5} \mathrm{~N}\left(\mathrm{C}_{16} \mathrm{H}_{33}\right)\right]_{3} \quad \mathrm{PO}_{4}\left[\mathrm{WO}_{3}\right]_{4}$ over 5 cycles with high yields for glutaric acid synthesis. ${ }^{119}$ Unfortunately, recovery issues and sharp loss of activity were observed generally after several recyclings. Moreover, surfactant-type POMs have to face some environmental issues to be obtained. They need non-negligible amounts of toxic organic volatile solvents such as benzene or dichloromethane and corrosive acids such as $\mathrm{H}_{3} \mathrm{PO}_{4}$ and $\mathrm{H}_{2} \mathrm{SO}_{4}$, in order to be produced via multiple steps of syntheses. ${ }^{85,86,97,110,119,120}$

\subsubsection{Oxidative systems based on tungstates}

\subsubsection{Combination with Phase Transfer Catalysts (onium salts)}

The substitution of POM catalysts becomes highly desirable in the design of environmentally-friendly oxidation conditions due to the impact of their synthesis on the environment. Indepth analysis of the species formed during the reaction between POMs and $\mathrm{H}_{2} \mathrm{O}_{2}$ reveal that these catalysts act as precursors of catalytically active species. Indeed, it has been shown that mono- and polymeric tungsten species resulting from POMs could be produced from simpler tungstate precursors in a similar way (Scheme 15). ${ }^{75,111}$
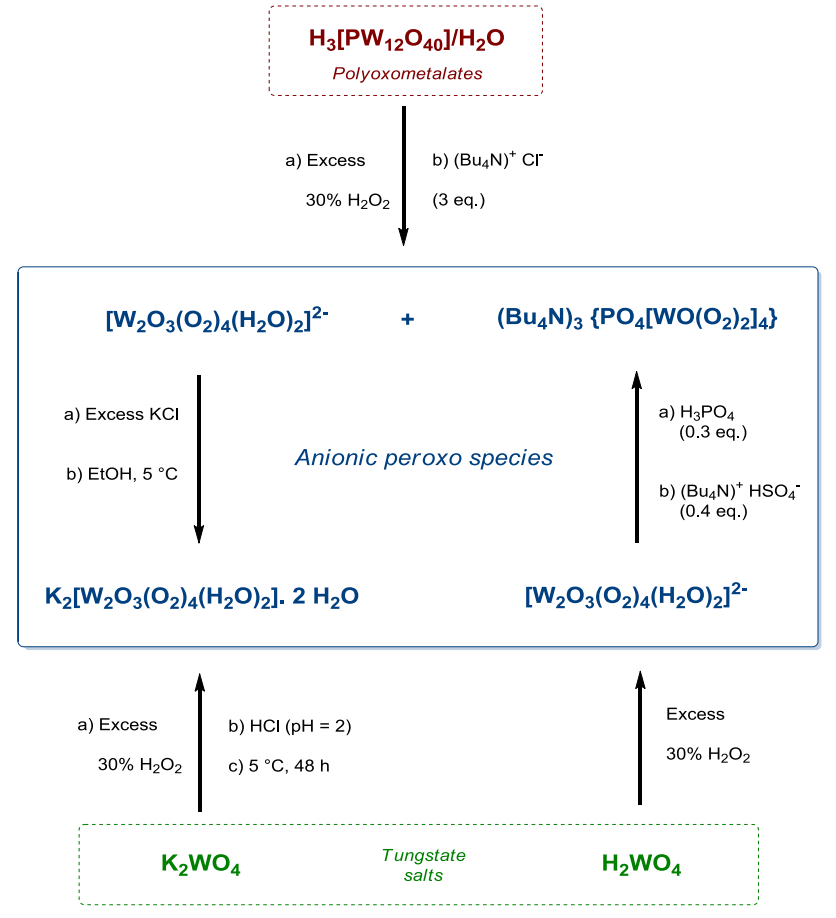
Scheme 15: Anionic peroxo species issued from the oxidation of POM or tungstate salts where isolated peroxo-compounds are illustrated in bold blue (adapted from Ref 111). 
Table 2 Homogeneous catalytic systems based on polyoxometalates reported for the oxidative cleavage of cycloalkenes in the presence of $\mathrm{H}_{2} \mathrm{O}_{2}$

\begin{tabular}{|c|c|c|c|c|c|c|c|c|}
\hline Entry & $\begin{array}{c}\text { Polyoxometalate } \\
\text { (POM) }\end{array}$ & Substrate & $\begin{array}{c}\text { Catalytic } \\
\text { system }\end{array}$ & PTC $^{a}$ & $\begin{array}{c}\text { Reaction } \\
\text { conditions }\end{array}$ & Product & Yield $^{\text {b }}$ & Ref \\
\hline 1 & $\mathrm{~W}_{2} \mathrm{O}_{3}\left(\mathrm{O}_{2}\right)_{4}^{2-}$ & Cyclohexene & $\begin{array}{c}\mathrm{POM}+ \\
\mathrm{H}_{2} \mathrm{O}_{2} 30 \% \\
\text { (5.4 eq.) }\end{array}$ & $\begin{array}{c}{\left[\pi-\mathrm{C}_{5} \mathrm{H}_{5} \mathrm{~N}\left(\mathrm{C}_{16} \mathrm{H}_{33}\right)\right]_{2}} \\
\mathrm{~W}_{2} \mathrm{O}_{3}\left(\mathrm{O}_{2}\right)_{4}\end{array}$ & $90^{\circ} \mathrm{C}, 20 \mathrm{~h}$ & Adipic acid & $78 \%$ & 113 \\
\hline 2 & & Cyclohexene & $\begin{array}{c}\mathrm{POM}+ \\
\mathrm{H}_{2} \mathrm{O}_{2} 30 \%(5.4 \\
\text { eq. })\end{array}$ & $\begin{array}{c}{\left[\mathrm{C}_{16} \mathrm{H}_{33} \mathrm{~N}\left(\mathrm{CH}_{3}\right)_{3}\right]_{3}} \\
\mathrm{~W}_{2} \mathrm{O}_{3}\left(\mathrm{O}_{2}\right)_{4}\end{array}$ & $90^{\circ} \mathrm{C}, 20 \mathrm{~h}$ & Adipic acid & $78 \%$ & 113 \\
\hline 3 & $\mathrm{PW}_{4} \mathrm{O}_{22}{ }^{3-}$ & Cyclohexene & $\begin{array}{c}\mathrm{POM}+ \\
\mathrm{H}_{2} \mathrm{O}_{2} 35 \%(4.4 \\
\text { eq. })\end{array}$ & $\begin{array}{c}{\left[\left(\mathrm{C}_{8} \mathrm{H}_{17}\right)_{3} \mathrm{NCH}_{3}\right]_{3}} \\
\mathrm{PW}_{4} \mathrm{O}_{22}\end{array}$ & $\begin{array}{l}\text { Dichloroethane, } \\
70^{\circ} \mathrm{C}, 16 \mathrm{~h}\end{array}$ & Adipic acid & $71 \%$ & 118 \\
\hline 4 & $\mathrm{PW}_{12} \mathrm{O}_{40}{ }^{3-}$ & Cyclopentene & $\begin{array}{c}\mathrm{POM}+ \\
\mathrm{H}_{2} \mathrm{O}_{2} 35 \%(4.4 \\
\text { eq. })\end{array}$ & $\begin{array}{c}{\left[\pi-\mathrm{C}_{5} \mathrm{H}_{5} \mathrm{~N}\left(\mathrm{C}_{16} \mathrm{H}_{33}\right)\right]_{3}} \\
\mathrm{PW}_{12} \mathrm{O}_{40}\end{array}$ & $\begin{array}{c}t \text {-BuOH, } \\
82^{\circ} \mathrm{C}, 24 \mathrm{~h}\end{array}$ & Glutaric acid & $66 \%$ & 86 \\
\hline 5 & & Cyclohexene & $\begin{array}{c}\mathrm{POM}+ \\
\mathrm{H}_{2} \mathrm{O}_{2} 35 \%(4.4 \\
\text { eq. })\end{array}$ & $\begin{array}{c}{\left[\pi-\mathrm{C}_{5} \mathrm{H}_{5} \mathrm{~N}\left(\mathrm{C}_{16} \mathrm{H}_{33}\right)\right]_{3}} \\
\mathrm{PW}_{12} \mathrm{O}_{40}\end{array}$ & $\begin{array}{c}t-\mathrm{BuOH}, \\
82^{\circ} \mathrm{C}, 24 \mathrm{~h}\end{array}$ & Adipic acid & $70 \%$ & 86 \\
\hline 6 & & $\begin{array}{l}\text { 1-Methyl-1- } \\
\text { cyclohexene }\end{array}$ & $\begin{array}{c}\mathrm{POM}+ \\
\mathrm{H}_{2} \mathrm{O}_{2} 35 \%(4.4 \\
\text { eq.) }\end{array}$ & $\begin{array}{c}{\left[\pi-\mathrm{C}_{5} \mathrm{H}_{5} \mathrm{~N}\left(\mathrm{C}_{16} \mathrm{H}_{33}\right)\right]_{3}} \\
\mathrm{PW}_{12} \mathrm{O}_{40}\end{array}$ & $\begin{array}{c}t-\mathrm{BuOH}, \\
82^{\circ} \mathrm{C}, 24 \mathrm{~h}\end{array}$ & $\begin{array}{l}\text { 5- } \\
\text { Oxohexanoic } \\
\text { acid }\end{array}$ & $90 \%$ & 86 \\
\hline 7 & & Cyclopentene & $\begin{array}{c}\mathrm{POM}+\mathrm{H}_{2} \mathrm{O}_{2} \\
30 \% \text { (or } 50 \% \text { ) } \\
\text { (4.4eq.) }\end{array}$ & $\begin{array}{c}{\left[\pi-\mathrm{C}_{5} \mathrm{H}_{5} \mathrm{~N}\left(\mathrm{C}_{16} \mathrm{H}_{33}\right)\right]_{3}} \\
\mathrm{PW}_{12} \mathrm{O}_{40}\end{array}$ & $85^{\circ} \mathrm{C}, 8 \mathrm{~h}$ & Glutaric acid & $\begin{array}{l}77 \%^{d} \\
(\text { or } \\
86 \%^{d} \text { ) }\end{array}$ & 119 \\
\hline 8 & $\left\{\mathrm{PO}_{4}\left[\mathrm{WO}_{3}\right]_{4}\right\}^{3-}$ & Cyclopentene & $\begin{array}{c}\mathrm{POM}+\mathrm{H}_{2} \mathrm{O}_{2} \\
30 \% \text { (or } 50 \% \text { ) } \\
\text { (4.4 eq.) }\end{array}$ & $\begin{array}{c}{\left[\pi-\mathrm{C}_{5} \mathrm{H}_{5} \mathrm{~N}\left(\mathrm{C}_{16} \mathrm{H}_{33}\right)\right]_{3}} \\
\mathrm{PO}_{4}\left[\mathrm{WO}_{3}\right]_{4}\end{array}$ & $85^{\circ} \mathrm{C}, 8 \mathrm{~h}$ & Glutaric acid & $\begin{array}{l}80 \%{ }^{d} \\
(\text { or } \\
83 \%^{d} \text { ) }\end{array}$ & 119 \\
\hline 9 & & Cyclohexene & $\begin{array}{c}\mathrm{POM}+ \\
\mathrm{H}_{2} \mathrm{O}_{2} 50 \%(3.3 \\
\text { eq. })\end{array}$ & $\begin{array}{c}{\left[\pi-\mathrm{C}_{5} \mathrm{H}_{5} \mathrm{~N}\left(\mathrm{C}_{16} \mathrm{H}_{33}\right)\right]_{3}} \\
\mathrm{PO}_{4}\left[\mathrm{WO}_{3}\right]_{4}\end{array}$ & $85^{\circ} \mathrm{C}, 5 \mathrm{~h}$ & Adipic acid & $85 \%{ }^{d}$ & 120 \\
\hline 10 & $\left\{\mathrm{PO}_{4}\left[\mathrm{~W}(\mathrm{O})\left(\mathrm{O}_{2}\right)_{2}\right]_{4}\right\}^{3-}$ & Cyclohexene & $\begin{array}{c}\mathrm{POM}+ \\
\mathrm{H}_{2} \mathrm{O}_{2} 30 \% \\
\text { (2 eq.) }\end{array}$ & $\begin{array}{c}{\left[\left(\mathrm{C}_{8} \mathrm{H}_{17}\right)_{3} \mathrm{NCH}_{3}\right]_{3}} \\
\mathrm{PO}_{4}\left[\mathrm{~W}(\mathrm{O})\left(\mathrm{O}_{2}\right)_{2}\right]_{4} \mathrm{e}^{2}\end{array}$ & $90^{\circ} \mathrm{C}, 3 \mathrm{~h}$ & Adipic acid & $\begin{array}{c}72 \% \\
(\text { Conv. } \\
85 \%)^{c}\end{array}$ & 121 \\
\hline 11 & & Cyclopentene & $\begin{array}{c}\mathrm{POM}+ \\
\mathrm{H}_{2} \mathrm{O}_{2} 40 \%(4.6 \\
\text { eq.) }\end{array}$ & $\begin{array}{c}{\left[\left(\mathrm{C}_{8} \mathrm{H}_{17}\right)_{3} \mathrm{NCH}_{3}\right]_{3}} \\
\mathrm{PO}_{4}\left[\mathrm{~W}(\mathrm{O})\left(\mathrm{O}_{2}\right)_{2}\right]_{4} \mathrm{e}\end{array}$ & $85^{\circ} \mathrm{C}, 7 \mathrm{~h}$ & Glutaric acid & $84 \%$ & 90 \\
\hline 12 & & Cyclohexene & $\begin{array}{c}\mathrm{POM}+ \\
\mathrm{H}_{2} \mathrm{O}_{2} 40 \%(4.4 \\
\text { eq.) }\end{array}$ & $\begin{array}{c}{\left[\left(\mathrm{C}_{8} \mathrm{H}_{17}\right)_{3} \mathrm{NCH}_{3}\right]_{3}} \\
\mathrm{PO}_{4}\left[\mathrm{~W}(\mathrm{O})\left(\mathrm{O}_{2}\right)_{2}\right]_{4} \mathrm{e}\end{array}$ & $85^{\circ} \mathrm{C}, 6 \mathrm{~h}$ & Adipic acid & $87 \%$ & 90 \\
\hline 13 & & $\begin{array}{l}\text { 1-Methyl-1- } \\
\text { cyclohexene }\end{array}$ & $\begin{array}{c}\mathrm{POM}+ \\
\mathrm{H}_{2} \mathrm{O}_{2} 40 \%(3.5 \\
\text { eq. })\end{array}$ & $\begin{array}{c}{\left[\left(\mathrm{C}_{8} \mathrm{H}_{17}\right)_{3} \mathrm{NCH}_{3}\right]_{3}} \\
\mathrm{PO}_{4}\left[\mathrm{~W}(\mathrm{O})\left(\mathrm{O}_{2}\right)_{2}\right]_{4} \mathrm{e}\end{array}$ & $85^{\circ} \mathrm{C}, 6 \mathrm{~h}$ & $\begin{array}{l}\text { 5- } \\
\text { Oxohexanoic } \\
\text { acid }\end{array}$ & $82 \%$ & 90 \\
\hline 14 & & Cycloheptene & $\begin{array}{c}\mathrm{POM}+ \\
\mathrm{H}_{2} \mathrm{O}_{2} 40 \%(4.6 \\
\text { eq.) }\end{array}$ & $\begin{array}{c}{\left[\left(\mathrm{C}_{8} \mathrm{H}_{17}\right)_{3} \mathrm{NCH}_{3}\right]_{3}} \\
\mathrm{PO}_{4}\left[\mathrm{~W}(\mathrm{O})\left(\mathrm{O}_{2}\right)_{2}\right]_{4}\end{array}$ & $85^{\circ} \mathrm{C}, 7 \mathrm{~h}$ & Pimelic acid & $68 \%$ & 90 \\
\hline
\end{tabular}


Among them, sodium tungstate and tungstic acid were well studied for the oxidative cleavage due to their ease of use, low cost and low toxicity. Yet, development of these catalysts require the use of Phase Transfer Catalysts (PTC) in order to carry out the oxidations under solventless conditions. Indeed, phase transfer agents are essential to allow species present in different non-miscible phases to react, as mass transfer constitutes a key limitation in biphasic conditions.

First uses of PTC in oxidation reactions were published by Starks describing the oxidative cleavage of 1-octene with aqueous neutral $\mathrm{KMnO}_{4}$ under biphasic conditions. ${ }^{122}$ The reaction, which did not proceed at room temperature under vigorous stirring for several hours, was instantaneous after addition of a little amount of a quaternary ammonium catalyst. C. Starks describes PTC as onium salts comprising a cationic moiety able to extract anions from the aqueous phase to the organic phase. ${ }^{123,124}$ Among the different classes of PTC, quaternary ammonium compounds are particularly efficient for oxidation reactions. ${ }^{\mathbf{8 8 , 1 2 5}}$

Different families of PTC were investigated in the presence of $\mathrm{Na}_{2} \mathrm{WO}_{4}$ to perform the oxidation reaction under solventless conditions. For instance, the oxidative cleavage of cyclohexene was studied in the presence of Varisoft $^{\circledR} 222$ [Bis(tallowamidoethyl)polyethoxymethylammonium

methosulfate]. Under these conditions, the introduction of phosphoric acid led to the production of the active $\left\{\mathrm{PO}_{4}\left[\mathrm{~W}(\mathrm{O})\left(\mathrm{O}_{2}\right)_{2}\right]_{4}\right\}^{3-}$. As observed in previous studies with POMbased catalysts, the complex results from the reaction between $\mathrm{Na}_{2} \mathrm{WO}_{4}, \mathrm{H}_{3} \mathrm{PO}_{4}$ and $\mathrm{H}_{2} \mathrm{O}_{2}$. However, 15 equivalents of $30 \% \mathrm{H}_{2} \mathrm{O}_{2}$ and $24 \mathrm{~h}$ were required to reach $99 \%$ yield of adipic acid, making the reaction non-economically attractive (Table 3 , Entry 1). ${ }^{126}$

In order to enhance the reaction in biphasic conditions, Perez et al. firstly described the use of $\mathrm{H}_{2} \mathrm{O}_{2}$ microemulsions as the oxidizing media for the oxidative cleavage of cyclohexene. ${ }^{127}$ This particular medium composed of oil droplets in nanodispersed in aqueous phase displays beneficial aspects for the reaction. Indeed, it allows performing organic synthesis in water, leads to fine dispersion of reactant within the oxidant and then increases local concentrations and reaction rates. Nevertheless, microemulsions require very high amounts of reactants to be stabilized. Specifically, 8:77:15 weight-ratios of cyclohexene, hydrogen peroxide and benzalkonium chloride respectively are needed to carry out the reaction. Compared to cyclohexene, this corresponds to 7 molar equivalents of hydrogen peroxide and almost 2 weight equivalents of the onium salt. In this case, the onium salt must be used in stoichiometric excess to stabilize microemulsions and thus plays the role of surfactant rather than PTC. Under these conditions, the reaction is completed in $18 \mathrm{~h}$ in the presence of $\mathrm{Na}_{2} \mathrm{WO}_{4}$ and $\mathrm{H}_{2} \mathrm{SO}_{4}$. (Table 3, Entry 2). ${ }^{127}$ The initial moderate $56 \%$ yield observed with microemulsions have been later improved by optimizing the reaction temperature rates. ${ }^{128}$ Indeed it has been shown that a step by step increase of the temperature from $75^{\circ} \mathrm{C}$ to $90^{\circ} \mathrm{C}$ is beneficial in many aspects of the reaction such as lower volatilization and faster conversion of cyclohexene and better $\mathrm{H}_{2} \mathrm{O}_{2}$ consumption. Such conditions lead to $80 \%$ adipic acid with reaction time shortened to $8 \mathrm{~h}$ (Table 3, Entry 3). In spite of these good results, microemulsions could hardly be implemented at the industrial scale. Indeed, very large amounts of reactants are required, the catalytic system is difficult to recycle and the reaction products are tediously extracted. ${ }^{127,128}$

Hence, continuous-flow microreactors have attracted the researchers' attention for the development of multiphasic reactions. Indeed, the microchannels of these continuous-flow reactors promote mass and heat transfer owing to the important surface to volume ratios (up to $10,000 \mathrm{~m}^{2} / \mathrm{m}^{3}$ ) reached by the micrometric size of the inner cavity (10 to 500 $\mu \mathrm{m}) .{ }^{129,130}$ These features enable continuous-flow microreactors to afford multiple benefits for oxidations reactions that mainly occur in multiphasic conditions. They allow intense mixing of non-miscible reactants, high mass transfer, fast dissipation of the heat produced during exothermic oxidation steps and working in explosive regimes by reason of low residence times of the reactants. ${ }^{131}$ Within this context, adipic acid synthesis has been recently reported by Hessel et al. under micro-flow conditions. After only 20 minutes of reaction at $100{ }^{\circ} \mathrm{C}$ in the presence of $\mathrm{H}_{2} \mathrm{SO}_{4}$ and $\mathrm{Oct}_{3} \mathrm{MeN}^{+} \mathrm{HSO}_{4}^{-}$, the oxidative cleavage of cyclohexene afforded pure adipic acid in 50\% yield. It is noteworthy that in the publication, the yield is based on the cyclohexene fraction that flew through the microreactor system, i.e. $30 \%$ of the total amount of charged reactant. Despite short residence times, this process unfortunately does not prevent the unavoidable decomposition of $\mathrm{H}_{2} \mathrm{O}_{2}$. Thus, these experimental conditions result in the formation of a triphasic system leading to non-replicable experiments (Table 3, Entry 4). ${ }^{130}$ However, the potential of micro-flow reactors for adipic acid synthesis has been recently highlighted by comparing the 2-step industrial production from cyclohexane with the one step cyclohexene oxidative cleavage with $\mathrm{H}_{2} \mathrm{O}_{2}$ in microchannels. Interestingly, considering only the equipment cost, simulations indicate that the one step adipic acid production is about $50 \%$ cheaper than 2 step KA oil process by lowering the amount and cost of pumps, compressors and dryers needed. ${ }^{129}$ Unfortunately these simulations do not take into account the cost of raw material which is however higher than those of the two-step route, thus limiting its implementation. Moreover, microflow systems still require some improvement, that would enable avoiding $\mathrm{H}_{2} \mathrm{O}_{2}$ decomposition and reach yields as high as those observed under batch conditions.

As catalytic systems involving sodium tungstate need low $\mathrm{pH}$ ranges $(<3)$ to prevent $\mathrm{H}_{2} \mathrm{O}_{2}$ decomposition and reach high dicarboxylic acid yields, the combination of $\mathrm{Na}_{2} \mathrm{WO}_{4}$ and 
$\mathrm{H}_{2} \mathrm{WO}_{4}$ was investigated for adipic acid synthesis. For instance, Reedijk and coworkers patented the use of both $\mathrm{Na}_{2} \mathrm{WO}_{4}$ and $\mathrm{H}_{2} \mathrm{WO}_{4}$ with Aliquat $336^{\circledR}$ (containing $\mathrm{Oct}_{3} \mathrm{MeN}^{+} \mathrm{Cl}^{-}$) and $\mathrm{ClCH}_{2} \mathrm{CO}_{2} \mathrm{H}$. Under these conditions and in the presence of 5 equivalents of $30 \% \mathrm{H}_{2} \mathrm{O}_{2}, 90 \%$ yield of adipic acid are obtained in only $4 \mathrm{~h}$ (Table 3, Entry 12 ). ${ }^{132}$ These excellent results for the oxidative cleavage of the unsaturated carbon-carbon bond are ascribed to chloroacetic acid by the authors, without any details or further information. In this patent, other cycloalkenes have been also studied but the only information available are their conversion (ranging from $67 \%$ to $99 \%$ between 40 and $\left.90{ }^{\circ} \mathrm{C}\right) .{ }^{126,132}$ In spite of these excellent conversions, efficiency of this catalytic system toward cycloalkenes oxidative cleavage is hardly assessable with other systems as no information on the corresponding dicarboxylic acid yields are given. Such reaction conditions would be very promising in terms of productivity if yields as high as $90 \%$ would be obtained from other cycloalkenes in only few hours, similarly to cyclohexene.

The $\mathrm{pH}$ of oxidation reactions involving the use of tungstates and PTC is important and usually the addition of an acid is required. Nevertheless, excellent results have been reported for the cyclohexene oxidative cleavage without the need of any external acidic source. In their study, Jiang and coworkers have evaluated various amino-based compounds such as PTC, in association with $\mathrm{Na}_{2} \mathrm{WO}_{4}$ to assess their activity and efficiency. Among the tertiary amines and quaternary ammoniums they studied, $n$-trioctylammonium dihydrogensulfate led to the best results with $94 \%$ yield in the presence of $27.5 \% \mathrm{H}_{2} \mathrm{O}_{2}$ after $5 \mathrm{~h}$ of reaction (Table 3, Entry 5). ${ }^{133}$ Despite the excellent results obtained with diluted $\mathrm{H}_{2} \mathrm{O}_{2}$, the homogeneous catalytic system displayed excellent activity for only one substrate example and suffered from low recyclability. Indeed, when the aqueous phase was used for an additional run by using 'fresh' PTC and $\mathrm{H}_{2} \mathrm{O}_{2}$, the adipic acid yield dropped from $94 \%$ to $70 \%$. Moreover, it is worth noting that the study by Jiang and coworkers was made to assess the efficiency of a catalytic system previously developed by Noyori and coworkers, and highlighted that molecular composition of $\mathrm{Oct}_{3} \mathrm{~N}_{\mathrm{H}} \mathrm{H}_{2} \mathrm{SO}_{4}$ is very close to the PTC firstly disclosed by the Noyori group.

Indeed, among the different studies on the oxidative cleavage of cycloalkenes with hydrogen peroxide, the ones from Prof. Noyori constituted a major breakthrough because of the development of environmentally friendly conditions. In these studies, the oxidative cleavage of cyclohexene is performed with $\mathrm{Na}_{2} \mathrm{WO}_{4}$ and $\mathrm{Oct}_{3} \mathrm{MeN}^{+} \mathrm{HSO}_{4}^{-}$as the PTC in the presence of 4.4 equivalents of $30 \% \mathrm{H}_{2} \mathrm{O}_{2}$ (Scheme 16). ${ }^{13,88}$ Under these conditions, adipic acid was produced in $90 \%$ isolated yield after $8 \mathrm{~h}$ between 75 and $90{ }^{\circ} \mathrm{C}$ under biphasic conditions (Table 3, Entry 6). Despite longer reaction times than those reported in previous works (Table 3, Entry 5), this catalytic system is the only example able to perform oxidative cleavages of various cycloalkenes and arenes at a $100 \mathrm{~g}$ scale. Using these conditions, cyclohexene derivatives have been converted to carboxylic acids with good to excellent yields (Table 3, Entries 7-9). Cyclopentene required $13 \mathrm{~h}$ of reaction to produce glutaric acid in $90 \%$ yield (Table 3, Entry 10). Cleavage of the $C(9)-C(10)$ double bond of phenanthrene required the use of aminomethylphosphonic acid leading to

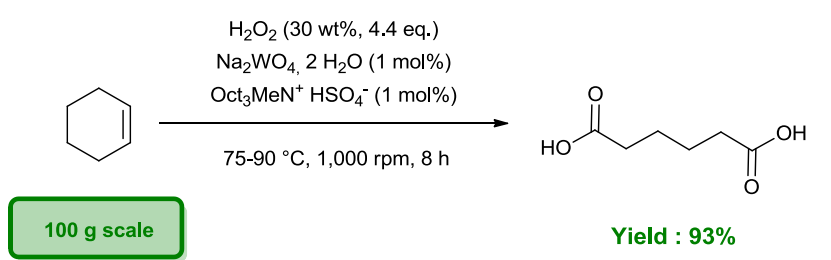

$41 \%$ yield of 2,2'-biphenyldicarboxylic acid. This halide and solvent free system constitute a real progress in comparison with reactions using energy demanding conditions and extensive amounts of chlorinated solvents. Scheme 16: : Halide and solvent free oxidative cleavage of cyclohexene by
hydrogen peroxide.

Among the studies using $\mathrm{Na}_{2} \mathrm{WO}_{4}$ and a PTC, the Oct $\mathrm{MeN}^{+}$ $\mathrm{HSO}_{4}{ }^{-}$firstly proposed by Noyori and coworkers generally leads to better results than other studied quaternary ammoniums (Table 3). Excellent results for dicarboxylic acid syntheses are explained by the combination of two physico-chemical properties of this PTC. Firstly, the lipophilicity of the cationic part allows bringing the active tungsten complex into the organic phase in order to oxidize the hydrophobic olefin. In addition, the acidity brought by hydrogensulfate anion is very important to maintain the active catalyst obtained at $\mathrm{pH}<3$ but also to carry out the different acidic steps of oxidative cleavage (Scheme 11 and 17). ${ }^{13,88,134}$

However, despite the versatility of $\mathrm{Oct}_{3} \mathrm{MeN}^{+} \mathrm{HSO}_{4}{ }^{-}$to perform a large variety of oxidations under eco-friendly conditions ${ }^{88}$, it cannot be considered sustainable because of a nonenvironmentally friendly synthesis. Indeed, toxic toluene, long reaction times and substantial amount of corrosive $\mathrm{H}_{2} \mathrm{SO}_{4}$ are required to produce this PTC. ${ }^{134}$ Thus, overall environmental aspect of oxidative cleavages is impacted by the toxic and harmful reactants used to produce this essential compound. ${ }^{134}$ Moreover, its high cost due to a multistep synthesis is also an obstacle for large scale applications. ${ }^{102,135}$

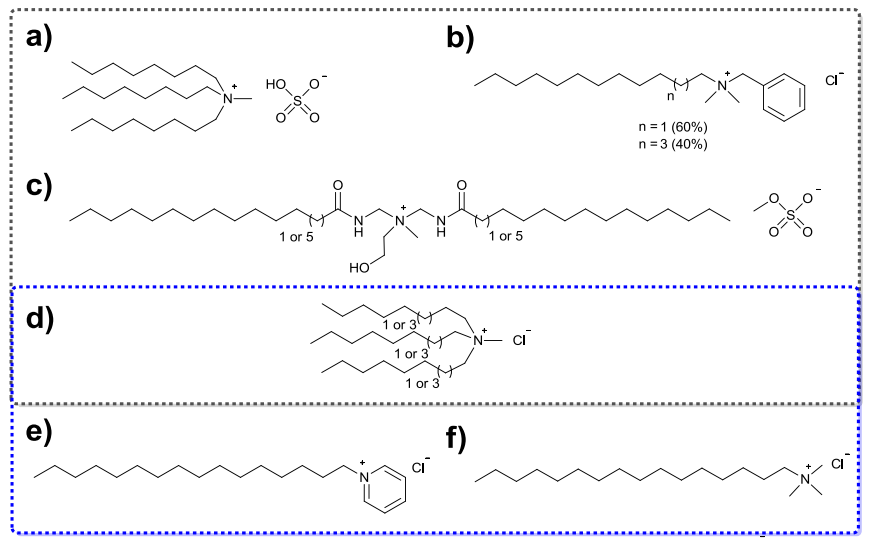


Scheme 17: Schematic representation of Phase Transfer Catalysts used for separately with the tungsage with hydrogen peroxide. Framed in grey: used new tungsten-based PTC when reacted with POM. a) Methyltrioctylammonium Hydrogensulfate, b) Benzalkonium Chloride, c) Varisoft $222^{\circledR}$, d) Aliquat $336^{\oplus}$, e Cetylpyridinium Chloride, f) Hexadecyltrimethylammonium Chloride. 
Table 3 Homogeneous catalytic systems based on $\mathrm{Na}_{2} \mathrm{WO}_{4}$ or $\mathrm{H}_{2} \mathrm{WO}_{4}$ and PTC reported for the oxidative cleavage of cycloalkenes with $\mathrm{H}_{2} \mathrm{O}_{2}$

\begin{tabular}{|c|c|c|c|c|c|c|c|c|}
\hline Entry & $\begin{array}{c}\text { Tungsten } \\
\text { oxide }\end{array}$ & Substrate & Catalytic system & PTC $^{a}$ & $\begin{array}{c}\text { Reaction } \\
\text { conditions }\end{array}$ & Product & Yield $^{\text {b }}$ & Ref. \\
\hline 1 & $\mathrm{Na}_{2} \mathrm{WO}_{4}$ & Cyclohexene & $\begin{array}{c}\mathrm{Na}_{2} \mathrm{WO}_{4}+\mathrm{H}_{3} \mathrm{PO}_{4}+ \\
\mathrm{H}_{2} \mathrm{O}_{2} 30 \% \text { (15 eq.) }\end{array}$ & Varisoft $222^{\circledR}$ & $90^{\circ} \mathrm{C}, 24 \mathrm{~h}$ & Adipic acid & $99 \%{ }^{c}$ & 126 \\
\hline 2 & & Cyclohexene & $\begin{array}{c}\mathrm{Na}_{2} \mathrm{WO}_{4}+ \\
\left.\mathrm{H}_{2} \mathrm{O}_{2} 30 \% \text { (7 eq. }\right)+ \\
\mathrm{H}_{2} \mathrm{SO}_{4}\end{array}$ & $\begin{array}{l}\text { Benzalkonium } \\
\text { Chloride }^{\mathrm{e}}\end{array}$ & $70^{\circ} \mathrm{C}, 18 \mathrm{~h}$ & Adipic acid & $\begin{array}{c}56 \%\left(76 \%{ }^{c}\right), \\
\text { up to } 97 \% \\
\text { (after } 5 \text { runs) }\end{array}$ & 127 \\
\hline 3 & & Cyclohexene & $\begin{array}{c}\mathrm{Na}_{2} \mathrm{WO}_{4}+ \\
\left.\mathrm{H}_{2} \mathrm{O}_{2} 30 \% \text { (7 eq. }\right)+ \\
\mathrm{H}_{2} \mathrm{SO}_{4}\end{array}$ & $\begin{array}{l}\text { Benzalkonium } \\
\text { Chloride }^{\mathrm{e}}\end{array}$ & $\begin{array}{l}75-85^{\circ} \mathrm{C}, \\
8 \mathrm{~h}\end{array}$ & Adipic acid & $\begin{array}{l}70 \% \text {, up to } \\
79 \% \text { (after } 4 \\
\text { runs) }\end{array}$ & 128 \\
\hline 4 & & Cyclohexene & $\begin{array}{c}\mathrm{Na}_{2} \mathrm{WO}_{4}+ \\
\left.\mathrm{H}_{2} \mathrm{O}_{2} 50 \% \text { (4.8 eq. }\right)+ \\
\mathrm{H}_{2} \mathrm{SO}_{4}\end{array}$ & $\underset{\mathrm{g}}{\mathrm{Oct}_{3} \mathrm{MeN}^{+} \mathrm{HSO}_{4}^{-}}$ & $\begin{array}{c}100{ }^{\circ} \mathrm{C} \text {, } \\
20 \mathrm{~min} \\
\text { (residence } \\
\text { time) }\end{array}$ & Adipic acid & $\begin{array}{c}50 \% \text { (based on } \\
30 \% \text { of } \\
\text { charged } \\
\text { reactant) }\end{array}$ & 130 \\
\hline 5 & & Cyclohexene & $\begin{array}{l}\mathrm{Na}_{2} \mathrm{WO}_{4}+\mathrm{H}_{2} \mathrm{O}_{2} \\
27.5 \% \text { (4.3 eq.) }\end{array}$ & $\mathrm{Oct}_{3} \mathrm{~N} . \mathrm{H}_{2} \mathrm{SO}_{4}$ & $\begin{array}{c}80-95^{\circ} \mathrm{C} \\
5 \mathrm{~h}\end{array}$ & Adipic acid & $94 \%$ & 133 \\
\hline 6 & & Cyclohexene & $\begin{array}{c}\mathrm{Na}_{2} \mathrm{WO}_{4}+\mathrm{H}_{2} \mathrm{O}_{2} 30 \% \\
\text { (4.4 eq.) }\end{array}$ & $\mathrm{Oct}_{3} \mathrm{MeN}^{+} \mathrm{HSO}_{4}^{-}$ & $\begin{array}{c}75-90^{\circ} \mathrm{C} \\
8 \mathrm{~h}\end{array}$ & Adipic acid & $\begin{array}{c}90 \% \\
\left(93 \%{ }^{c}\right)\end{array}$ & 13,88 \\
\hline 7 & & $\begin{array}{l}\text { Cyclohexene-4,5- } \\
\text { dicarboxylic } \\
\text { anhydride }\end{array}$ & $\begin{array}{c}\mathrm{Na}_{2} \mathrm{WO}_{4}+\mathrm{H}_{2} \mathrm{O}_{2} 30 \% \\
\text { (4.4 eq.) }\end{array}$ & $\mathrm{Oct}_{3} \mathrm{MeN}^{+} \mathrm{HSO}_{4}^{-}$ & $\begin{array}{c}75-90^{\circ} \mathrm{C} \\
8 \mathrm{~h}\end{array}$ & $\begin{array}{c}\text { Meso-1,2,3,4- } \\
\text { butanetetracarboxylic } \\
\text { acid }\end{array}$ & $91 \%$ & 13,88 \\
\hline 8 & & $\begin{array}{l}\text { Cyclohexene-4,5- } \\
\text { dicarboxylic acid }\end{array}$ & $\begin{array}{c}\mathrm{Na}_{2} \mathrm{WO}_{4}+\mathrm{H}_{2} \mathrm{O}_{2} 30 \% \\
\text { (4.4 eq.) }\end{array}$ & $\mathrm{Oct}_{3} \mathrm{MeN}^{+} \mathrm{HSO}_{4}^{-}$ & $\begin{array}{c}75-90^{\circ} \mathrm{C} \\
8 \mathrm{~h}\end{array}$ & $\begin{array}{c}\text { Meso-1,2,3,4- } \\
\text { butanetetracarboxylic } \\
\text { acid }\end{array}$ & $96 \%$ & 13,88 \\
\hline 9 & & $\begin{array}{l}\text { 1-Methyl- } \\
\text { Cyclohexene }\end{array}$ & $\begin{array}{c}\mathrm{Na}_{2} \mathrm{WO}_{4}+\mathrm{H}_{2} \mathrm{O}_{2} 30 \% \\
\text { (4.4 eq.) }\end{array}$ & $\mathrm{Oct}_{3} \mathrm{MeN}^{+} \mathrm{HSO}_{4}^{-}$ & $\begin{array}{c}75-90^{\circ} \mathrm{C} \\
8 \mathrm{~h}\end{array}$ & 6-Oxoheptanoic acid & $59 \%$ & 13,88 \\
\hline 10 & & Cyclopentene & $\begin{array}{c}\mathrm{Na}_{2} \mathrm{WO}_{4}+\mathrm{H}_{2} \mathrm{O}_{2} 30 \% \\
\text { (4.4 eq.) }\end{array}$ & $\mathrm{Oct}_{3} \mathrm{MeN}^{+} \mathrm{HSO}_{4}^{-}$ & $\begin{array}{c}70-90^{\circ} \mathrm{C} \\
13 \mathrm{~h}\end{array}$ & Glutaric acid & $90 \%$ & 13,88 \\
\hline 11 & & Phenanthrene & $\begin{array}{c}\mathrm{Na}_{2} \mathrm{WO}_{4}+ \\
\mathrm{H}_{2} \mathrm{O}_{2} 30 \% \text { (4.4 eq.) }+ \\
\mathrm{NH}_{2} \mathrm{CH}_{2} \mathrm{PO}_{3} \mathrm{H}_{2}\end{array}$ & $\mathrm{Oct}_{3} \mathrm{MeN}^{+} \mathrm{HSO}_{4}^{-}$ & $\begin{array}{c}75-90^{\circ} \mathrm{C} \\
8 \mathrm{~h}\end{array}$ & $\begin{array}{l}\text { 2,2'-Biphenyl- } \\
\text { dicarboxylic acid }\end{array}$ & $41 \%$ & 13,88 \\
\hline 12 & $\begin{array}{c}\mathrm{Na}_{2} \mathrm{WO}_{4}+ \\
\mathrm{H}_{2} \mathrm{WO}_{4}\end{array}$ & Cyclohexene & $\begin{array}{c}\mathrm{Na}_{2} \mathrm{WO}_{4}+\mathrm{H}_{2} \mathrm{WO}_{4}+ \\
\mathrm{H}_{2} \mathrm{O}_{2} 30 \% \text { (5 eq.) }+ \\
\mathrm{ClCH}_{2} \mathrm{CO}_{2} \mathrm{H}\end{array}$ & Aliquat $336^{{ }^{f}}$ & $90^{\circ} \mathrm{C}, 4 \mathrm{~h}$ & Adipic acid & $90 \%$ & 132 \\
\hline & ${ }^{d}$ Variso & $\begin{array}{l}\text { Phase Transfer } \mathrm{Ca} \\
22{ }^{\circledR}=\left[\left(\mathrm{C}_{13}-\mathrm{C}_{17}-\mathrm{CO}\right.\right. \\
{ }^{\mathrm{f}} \text { Aliquat } 336{ }^{\circledR}=\end{array}$ & $\begin{array}{l}\text { lyst. }{ }^{b} \text { Unless otherw } \\
\left.\left.\mathrm{AC}_{2} \mathrm{H}_{4}\right) \mathrm{N}\left(\mathrm{C}_{2} \mathrm{H}_{4} \mathrm{OH}\right) \mathrm{CH}_{3}\right][\mathrm{S} \\
\text { ajority of } \mathrm{Oct}_{3} \mathrm{MeN}^{+} \mathrm{Cl}^{-}\end{array}$ & $\begin{array}{l}\text { e stated, refers } \\
\left.{ }_{3}\left(\mathrm{OCH}_{3}\right)\right] .{ }^{\mathrm{e}} \text { Benzal } \\
\text { Minority of }\left(\mathrm{C}_{10} \mathrm{H}_{2}\right.\end{array}$ & $\begin{array}{l}\text { isolated yie } \\
\text { nium chlorid } \\
\mathrm{MeN}^{+} \mathrm{Cl}^{-}{ }^{\mathrm{g}} \mathrm{Sy}\end{array}$ & $\begin{array}{l}\text { Yield based on GC ana } \\
3 \mathrm{nMe}_{2} \mathrm{RN}^{+} \mathrm{Cl}^{-}\left(\mathrm{R}=\mathrm{C}_{12}: 60 \%\right. \\
\text { esized from Aliquat } 336\end{array}$ & $\left.\mathrm{C}_{14}: 40 \%\right)$. & \\
\hline
\end{tabular}

Thus, in spite of environmentally friendly conditions offered by such catalytic systems, problems of recovery of phase transfer material and its co-precipitation with solid diacids make them hardly applicable for large scale synthesis. ${ }^{103}$ For these reasons, researchers also investigated biphasic conditions for the oxidative cleavage of cycloalkenes but without addition of any phase transfer material.

\subsubsection{Phase Transfer Catalyst-free systems}

Among the PTC-free catalytic systems studied for oxidative cleavages with $\mathrm{H}_{2} \mathrm{O}_{2}$, ionic liquids (IL) have attracted much attention for many years. Indeed, these salts display interesting physico-chemical properties such as a low melting point (below $100{ }^{\circ} \mathrm{C}$ ), low vapour pressure and high chemical and thermal stability for applications in organic chemistry. ${ }^{136}$ 
Recently, a strong interest in the use of ionic liquids for catalysed reactions has emerged due to their versatile properties affecting the rate of some reactions and their ability to immobilize catalysts. ${ }^{137,138}$ This latter feature allows catalysts to be recycled when combined with ionic liquids. Accordingly, application of these particular solvents in wide variety of oxidation reactions has been comprehensively reviewed. ${ }^{139,140}$

Among the different ionic liquids studied for the oxidative cleavage of alkenes, IL based on imidazolium cations have been the most described in the literature followed by pyridinium and ammonium-based ones. Hashemi et al. engaged pioneering studies on ionic liquids for adipic acid synthesis by developing various specific systems. The first system describes a silica supported acid catalyst obtained by impregnation with task-specific ionic liquid (Scheme 18, left). Here, the system combines numerous interesting features and benefits for the reaction such as the recyclability of the heterogeneous support, the Brønsted acidity of the sulfamic acid group grafted on the chain, the thermal and chemical stability of $[\mathrm{BMIm}]_{2} \mathrm{WO}_{4}$ and the immobilization of the active tungsten-based catalyst. After $18 \mathrm{~h}$ of reaction at $75^{\circ} \mathrm{C}$ with 4.4 eq. $\mathrm{H}_{2} \mathrm{O}_{2}$, this semi-heterogeneous system leads to $87 \%$ yield of adipic acid. ${ }^{141} \mathrm{~A}$ recyclability test gave $79 \%$ yield after a second run. However, no more recycling test were implemented and the slight decrease of yield has been attributed to a loss of ionic liquid during catalyst washing steps. Thus, catalyst recovery constituting a major issue in homogenous catalysis, a system combining a new task-specific ionic liquid with silver tungstate nanorods has been developed. In this work, 1,2-dimethyl substituted imidazolium is believed to prevent the ionic liquid from progressive oxidation during reaction (Scheme 18, right). ${ }^{142}$ The presence of the dodecyl chain on the imidazolium moiety enhanced the miscibility of the catalytic system with organic substrates. Moreover, the hydrogensulfate anion of the ionic liquid allowed reaching the low $\mathrm{pH}$ values required for the reaction. Such properties led the designed ionic liquid to act as a surfactant-type Brønsted acid. Finally, the system was more easily prepared than the silica-supported one, and afforded adipic acid in $85 \%$ yield after $18 \mathrm{~h}$ at $75^{\circ} \mathrm{C} .{ }^{142}$ Nevertheless, its recyclability was demonstrated through only a second reuse of the concentrated mother liquor from the first run.

As semi-heterogeneous catalytic systems require long reaction times to perform the reaction, imidazolium-based task-specific ionic liquids have been studied alone. For instance, the $[\mathrm{BMIm}]_{2} \mathrm{WO}_{4}$, previously reported in combination with silicabased support ${ }^{141}$ (Scheme 18, left) was synthesized and used for cyclopentene oxidative cleavage with $30 \% \mathrm{H}_{2} \mathrm{O}_{2} \cdot{ }^{143}$ Such conditions would enhance the environmental character of the reaction that commonly involves toxic cyanides and releases poisonous hydrogen cyanide $\mathrm{HCN}$ into the environment. ${ }^{143}$
After $11 \mathrm{~h}$ of reaction between 50 and $80{ }^{\circ} \mathrm{C}$ in the presence of [BMIm $]_{2} \mathrm{WO}_{4}$ and $p$-toluenesulfonic acid, glutaric acid was obtained in $87 \%$ yield. ${ }^{143}$ Reusability of the ionic liquid-based system also proved to be efficient over 4 cycles. However, progressive catalyst loss is often observed along catalyst recycling and is probably responsible for the yield decrease from $87 \%$ to $70 \%{ }^{143}$

Another "dimethyl" substituted imidazolium-based ionic liquid has also been investigated by Hashemi et al. for the cyclohexene oxidative cleavage. This particular ionic liquid displays a strong acidity brought by the sulfonated alkyl chain on the imidazolium cation and an oxidizing activity due to the tungstate anion (Scheme 18, center). This homogeneous system afforded adipic acid in $85 \%$ yield after $14 \mathrm{~h}$ of reaction

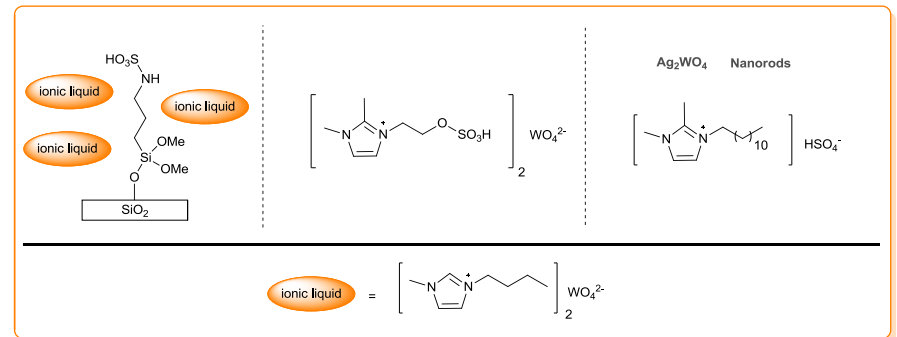

between 70 and $90{ }^{\circ} \mathrm{C} .{ }^{144}$ The oxidative cleavage of 1,4cyclooctadiene and cyclopentene were also performed under these conditions leading to $88 \%$ and $79 \%$ yields of succinic and glutaric acids respectively. ${ }^{144}$

Scheme 18: Ionic liquid-based systems developed for the oxidative cleavage of cyclohexene with $\mathrm{H}_{2} \mathrm{O}_{2}$.

Different imidazolium, pyridinium and ammonium-based ionic liquids were also studied by Jiang et al. in order to assess their stability and activity during the cyclohexene oxidative cleavage. Previous studies of the Jiang group on the substitution of PTC by organic ligands highlighted the importance of their acidity for the reaction. These results led the group to design acidic ionic liquids able to replace PTC. ${ }^{133,145,146}$ The comparison of acidic ionic liquids with neutral

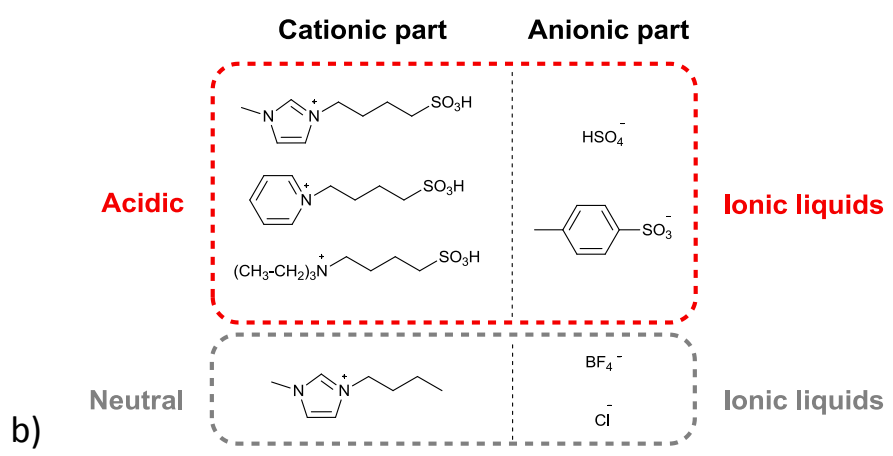

ones highlighted the impact of their acidic character on the production of adipic acid (Scheme 19).

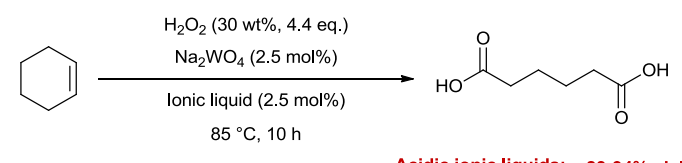

Acidic ionic liquids: $\quad 83-94 \%$ yield Neutral ionic liquids: $38-42 \%$ yield 
Scheme 19: Oxidative cleavage of cyclohexene with $\mathrm{Na}_{2} \mathrm{WO}_{4}$ and $\mathrm{H}_{2} \mathrm{O}_{2}$ in the presence of various ionic liquids. a) Studied ionic liquids. Circled in red: acidic ime conventional neutra

Indeed, while a maximum $42 \%$ yield is obtained with neutral ionic liquids based on chloride and tetrafluoroborate anions, sulfonic acid containing ILs allowed to reach more than $80 \%$ yields (Scheme 19). For instance, $94 \%$ yield of adipic acid was obtained after $10 \mathrm{~h}$ reaction at $85{ }^{\circ} \mathrm{C}$ in the presence of 2.5 mol\% $\left[\left(\mathrm{CH}_{2}\right)_{4} \mathrm{SO}_{3} \mathrm{HMIm}\right][$ Tos $]$. ${ }^{146}$

Unfortunately, even if ionic liquids are promising solvents because of their tunable physico-chemical properties, their implementation at the industrial scale still faces major issues. Indeed, their non-environmentally friendly multi-step synthesis and consecutive purifications make the generalization of their use not-economically viable. As an illustration, ionic liquids used for $\mathrm{H}_{2} \mathrm{O}_{2}$-mediated oxidative cleavage require 2 to 4 reaction steps in toxic solvents (toluene, dichloromethane) and long reaction times each (up to $48 \mathrm{~h}$ ) to be produced. ${ }^{142,144}$ In addition, the possibility of their re-usability has not been proved via multiple recyclability tests.

In order to substitute quaternary ammonium-based compounds that are usually polluting, some organic complexing agents have been proposed and tested with tungstate and peroxotungstate catalysts. Among them, bidendate ligands are well known for $\mathrm{H}_{2} \mathrm{O}_{2}$-mediated organic oxidations. Indeed, alcohol oxidation with picolinate chelated peroxotungstate catalyst was the first example described by

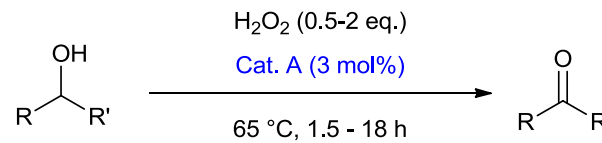

C4 to $\mathrm{C} 7$ cyclic alcohols: $\mathbf{1 4}-\mathbf{5 5} \%$ Yield

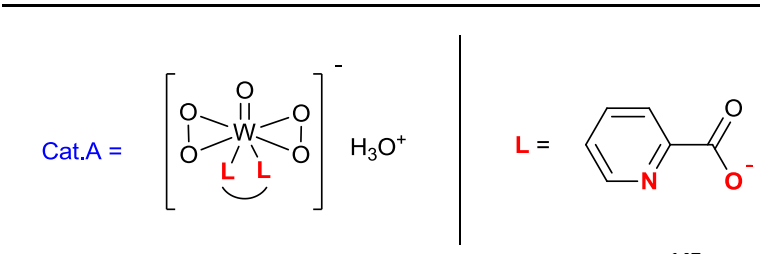

Jacobson and Mares in the late 70's (Scheme 20). ${ }^{147}$
Scheme 20: Secondary alcohol oxidation with hydrogen peroxide involving peroxotungstate complex chelated by picolinate ligand.

On this basis, different families of organic chelating agents for tungsten have been developed to perform the oxidative cleavage of cyclohexene. For instance, nitrogen-based ligands such as 8-hydroxyquinoline or 10-phenantroline have been used for the preparation of oxodiperoxo complex $\left[\mathrm{W}(\mathrm{O})\left(\mathrm{O}_{2}\right)_{2}(\mathrm{~L})_{2}\right]^{-}$. More specifically, chelated peroxotungstate complexes were obtained by mixing $\mathrm{WO}_{3}, \mathrm{H}_{2} \mathrm{O}_{2}$ and the organic ligands prior to their use. Such catalysts afforded adipic acid with yields over $80 \%$ (Scheme 21). ${ }^{148,149}$ Nevertheless, the reaction required a higher $\mathrm{H}_{2} \mathrm{O}_{2}$ amount than the one used in previous works (5.4 eq. instead of usual 4.4 eq.) and $20 \mathrm{~h}$ reaction to achieve yields above $80 \%$. Similar catalyst preparation procedure was applied with pyridine as a monodendate ligand. The catalytic complex obtained proved its efficiency for the oxidative cleavage of chiral dibenzylester derivative of cyclohexene within only $4 \mathrm{~h}$ reaction with $79 \%$ yield. ${ }^{150}$ Interestingly, Ford et al. proposed the addition of acetic acid into the media to reach milder $\mathrm{pH}$ conditions than Noyori hence preventing ester functions from hydrolysis. Nevertheless, despite shorter reaction times, this methodology has not been applied for the oxidative cleavage of cyclohexene or other cycloalkenes.

Some oxygen-based ligands were also investigated as chelating agents in combination with sodium tungstate. Deng et al. described the first solvent and PTC-free synthesis of adipic acid with a system involving oxalic acid (Scheme 21). ${ }^{135}$ Later, Jiang et al. improved these conditions by decreasing the reaction time from $24 \mathrm{~h}$ to $8 \mathrm{~h}$. Among the 46 ligands tested, sulfosalycilic acid used in $2.5 \mathrm{~mol} \%$ afforded the best results, leading to $88 \%$ adipic acid yield (Scheme 21 ). ${ }^{145}$ Once more, even if no complete characterization of the active specie was described in this work, the authors highlighted the need of mixing catalyst, ligand and $\mathrm{H}_{2} \mathrm{O}_{2}$ together to form an active peroxotungstate species prior to the addition of the substrate. $^{135,145}$

More recently, the association of a polyoxometalate with an amino-acid resulted in the formation of a new heteropolysalt. ${ }^{151}$ This Keggin-type catalyst comprising a protonated glycine and phosphotungstate ions has been wellcharacterized and showed similar behaviours as previous surfactant-type polyoxometalates. Emulsifying effect and strong acidity of this complex led Wang et al. to perform the cyclohexene oxidative cleavage with excellent $95 \%$ yield after $12 \mathrm{~h}$ of reaction in the presence of only $0.2 \mathrm{~mol} \%$ catalyst (Scheme 21). ${ }^{151}$ 


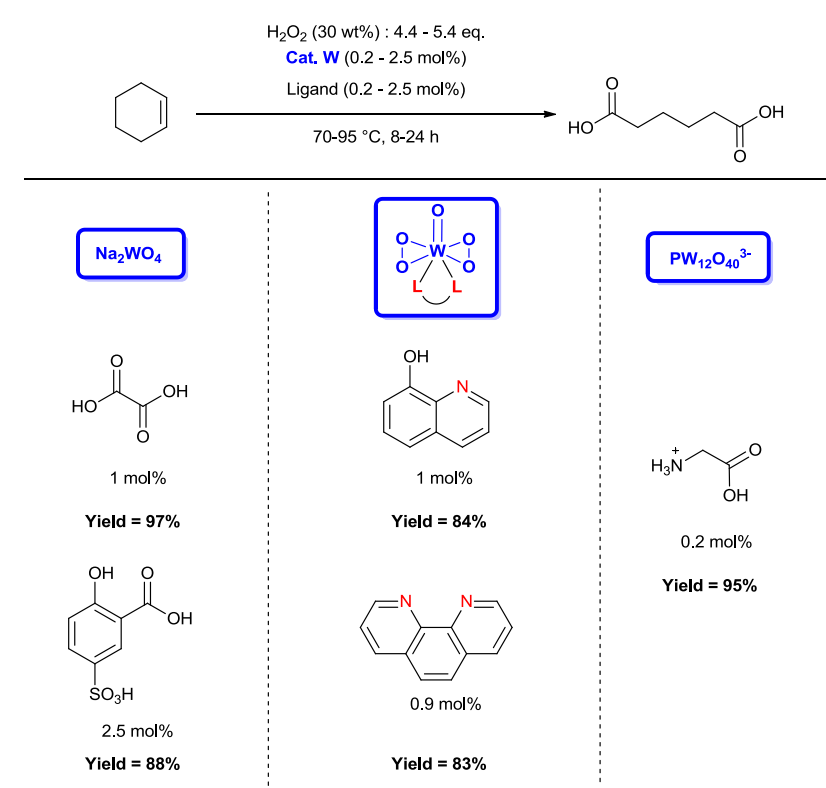

Scheme 21: Organic ligands, us d $_{35,145,148,149,151}$ in phase transfer catalyst-free oxidative cleavage of cyclohexene.

These excellent results can be explained by key features. Firstly, a mild to strong acidity appeared to be essential to reach high dicarboxylic acid yields by favouring the acidic steps. ${ }^{135,145}$

However, the chelating activity of the ligand was shown to be more important than its acidity to enhance the activity of the catalyst. ${ }^{145}$ Moreover, the formation of single chelate ring would also lead to better oxidative cleavage results. A strong affinity of the ligands with the organic phase would increase the lipophilicity of the active tungsten species hence ensuring the compatibility with organic substrates. ${ }^{135,145}$

Interaction of the peroxotungsten species with electrondonating atoms has also been pointed out as an important factor to increase the oxidizing power of the catalyst. In fact, for some dimeric tungsten species such as $\left[\mathrm{W}_{2} \mathrm{O}_{3}\left(\mathrm{O}_{2}\right)_{4}\right]^{2-}$, the presence of two asymmetrically bounded $\eta^{2}$-peroxide ligands was shown to weaken the $\mathrm{W}-\mathrm{O}$ bond and make it easier to break (Scheme 13). ${ }^{85}$ In a similar way, the chelating effects of nitrogen or oxygen containing ligands would lower the bond energy between $\mathrm{W}$ and the peroxide function making it more reactive toward olefins.

Oxidative cleavage of cycloolefins has also been studied without any organic additive, by only mixing the substrate, a tungsten salt as catalyst and hydrogen peroxide. In these conditions, tungsten salts were mainly described as they enable the production of carboxylic acids while tungsten oxides led to the formation of aldehydes. Indeed, after $20 \mathrm{~h}$ at $35{ }^{\circ} \mathrm{C}$ with 2 eq. $\mathrm{H}_{2} \mathrm{O}_{2}$ and $\mathrm{WO}_{3}$ as the catalyst, oxidative cleavage of cyclohexene and cyclopentene afforded adipaldehyde and glutaraldehyde in 50 to $80 \%$ yield respectively. ${ }^{152}$

In the development of organic additive-free conditions for adipic acid synthesis, Ishii engaged pioneering works by improving its first system based on cetylpyridinium catalyst. ${ }^{153}$
Thus, the research group reported the first PTC-free oxidative cleavage of cyclohexene mediated by tungstic acid. However, the reaction required 5 wt\% of $\mathrm{H}_{2} \mathrm{WO}_{4}$ and $t-\mathrm{BuOH}$ as solvent to reach a moderate $62 \%$ yield after $24 \mathrm{~h}$ at $95{ }^{\circ} \mathrm{C} .{ }^{153}$ Similar moderate yields reaching $48 \%$ and $72 \%$ were also observed from cyclopentene and 1-methyl-cyclohexene, respectively.

Tungstophoshoric acid was proposed by Fujitani et al. for the biphasic oxidative cleavage of various cycloalkenes in the presence of $60 \% \mathrm{H}_{2} \mathrm{O}_{2}$. Under these conditions, cyclohexene derivatives were successfully converted into their corresponding polycarboxylic acids with yields from 86 to $95 \%$ in $8 \mathrm{~h}$ to $15 \mathrm{~h}$ without any solvent and phase transfer material. $^{154}$

The $\mathrm{H}_{2} \mathrm{WO}_{4}-\mathrm{H}_{2} \mathrm{O}_{2}$ oxidizing system also proved its efficiency for adipic synthesis in micro-flow reactors. The reactions were carried out in a system consisting of two glass syringe pumps, a T-mixer, a residence tube, and an adjustable stainless steel back pressure regulator. Using this system, cyclohexene oxidative cleavage was performed at $140{ }^{\circ} \mathrm{C}$ over an hour with 20 min residence time and resulted in $73 \%$ isolated yield. ${ }^{155}$ In spite of safe operations conditions allowed by continuous micro-flow systems under high temperatures, such systems still need to be improved. Indeed, side-reactions are observed and $\mathrm{H}_{2} \mathrm{O}_{2}$ decomposition occurs during the reaction due to reactor-wall effects coming from the high surface-to-volume ratio. ${ }^{129,130,155} \mathrm{H}_{2} \mathrm{WO}_{4}-\mathrm{H}_{2} \mathrm{O}_{2}$ system was also used for the selective oxidation of cyclopentene to glutaric acid under solvent and PTC-free conditions. In the presence of $1.5 \mathrm{~mol} \%$ of catalyst and $30 \%$ or $50 \% \mathrm{H}_{2} \mathrm{O}_{2}$, yields over $80 \%$ were reached after $8 \mathrm{~h}$ of reaction. ${ }^{119}$

As acidity plays a pivotal role within reaction mechanisms, some inorganic acids were also investigated to study their influence on the outcomes of the reaction. Tang and Wang et al. studied the product distribution following the conditions of cyclohexene oxidative cleavage. Among the parameters tested, the influence of the amount of added $\mathrm{H}_{2} \mathrm{SO}_{4}$ on adipic acid yield and by-products formation was studied. An optimal amount of $6.5 \mathrm{~mol} \%$ of $\mathrm{H}_{2} \mathrm{SO}_{4}$ in the presence of $2 \mathrm{~mol} \%$ of $\mathrm{Na}_{2} \mathrm{WO}_{4}$ and 4.4 eq. of $30 \% \mathrm{H}_{2} \mathrm{O}_{2}$ were proven optimal to afford adipic acid in $95 \%$ yield in only $6 \mathrm{~h} .{ }^{156}$ On the basis of this work and previous studies, the same research group reported the first large-scale continuous-flow oxidative cleavage of cyclohexene with hydrogen peroxide. Combined use of sulfuric acid and phosphoric acid was described as essential to
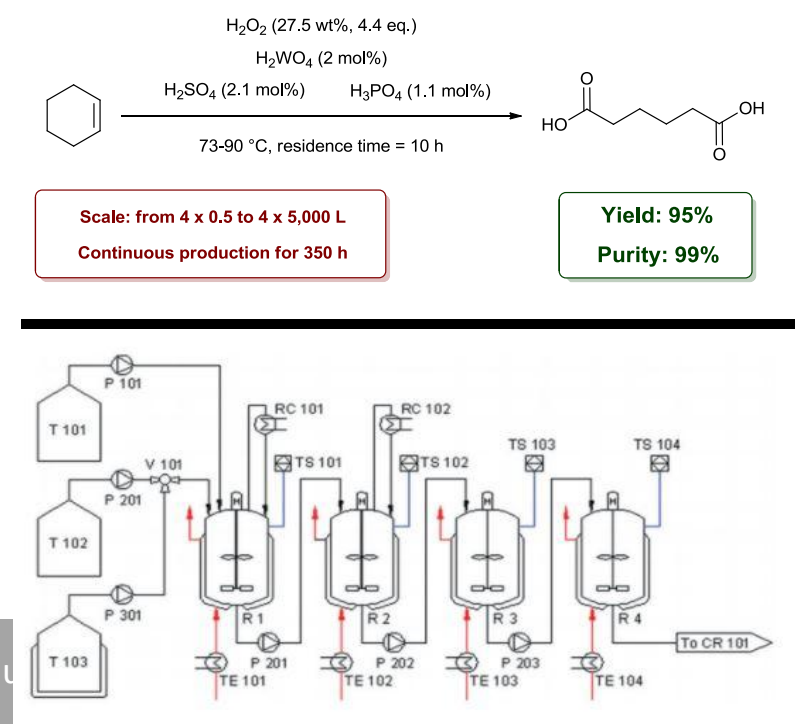
promote the acidic steps of the reaction and to prevent $\mathrm{H}_{2} \mathrm{O}_{2}$ decomposition during successive runs respectively. Optimisation of the reaction conditions with the $\mathrm{H}_{2} \mathrm{WO}_{4}$ $\mathrm{H}_{2} \mathrm{SO}_{4}-\mathrm{H}_{3} \mathrm{PO}_{4}-\mathrm{H}_{2} \mathrm{O}_{2}$ system allowed to scale up the reaction up to four 5,000 L continuous stirred tank reactors. For the first time, the group succeeded to develop the large scale synthesis of $99 \%$ pure adipic acid without any PTC with a $95 \%$ yield (Scheme 22). ${ }^{157}$ Efficiency of this large scale process was evidenced with $350 \mathrm{~h}$ continuous production of adipic acid associated to excellent yields and limited $\mathrm{H}_{2} \mathrm{O}_{2}$ decomposition. This unique PTC and solvent-free process illustrates the relevance of $\mathrm{W}-\mathrm{H}_{2} \mathrm{O}_{2}$ oxidizing systems at industrial scale for the production of carboxylic acids of interest under environmentally-friendly conditions.

Scheme 22: Example of large scale production of adipic acid through $\mathrm{H}_{2} \mathrm{O}_{2}$ mediated oxidative cleavage: Scheme of the reaction (up) and schematic permission from The Royal Society of Chemistry)

Future challenges for such homogeneous catalytic systems will rely on their recyclability for consecutive runs. Interestingly, Zheng, Wang and $\mathrm{Li}$ et al. developed a simple $\mathrm{pH}$-controlled method to precipitate selectively tungsten oxides from mother liquors isolated at the end of reactions. ${ }^{158}$ This easy method exhibits high recovery rates and allows recovered $\mathrm{WO}_{3}$ to display the same activity as fresh catalyst for a single run of adipic acid synthesis. Nevertheless, it could be interesting to combine this method with strategies using reaction mother liquors for several consecutive runs. ${ }^{13,141,143,144,157}$

As soon as the performances of the catalytic system begin to decrease along reactions, tungsten catalyst could be recovered and integrated again in a fresh oxidizing system for new consecutive syntheses.

\section{Limits of hydrogen peroxide-mediated oxidative cleavage of cycloalkenes}

\subsection{The case of medium-size cycloalkenes}

As illustrated previously, catalytic systems for cycloalkene oxidative cleavage with hydrogen peroxide have mainly been studied with cyclohexene as the model compound. This starting material is of particular interest due to the challenges offered by the current $\mathrm{HNO}_{3}$-based process for adipic acid production. More specifically, the possibility of using $\mathrm{H}_{2} \mathrm{O}_{2}$ as primary oxidant in a one-step reaction would represent a successful example of integration of a green strategy into an industrial process.

However, the opportunity to improve the actual KA oil process only represents the tip of the iceberg. As previously illustrated, the high reactivity of the cyclohexene double bond and its oxidation products in the presence of $\mathrm{H}_{2} \mathrm{O}_{2}$ have also to be taken into account when choosing this model compound.

But one of the issue of oxidative cleavage of cycloalkenes is to limit the formation of undesired shorter diacids. Often observed along with terminal keto-acids, their formation has not been fully understood to date. ${ }^{13,29,90,93,96}$ Even if Density Functional Theory calculations have explained their formation through specific intermediates, they haven't been detected during analyses yet. ${ }^{93}$ In most of cases, these by-products are formed in low quantities (from 1 to 5\%) within studies with small-sized cycloalkenes.

While very efficient with strained cycloalkenes, the tungstenbased systems also reach their limit when they are used for the oxidative cleavage of medium-sized cycloalkenes. Indeed, as illustrated in the Table 4, the few reports published on the oxidative cleavage of medium-sized cycloalkenes showed that the larger the cycle, the lower the results. At reasonable reaction time and $\mathrm{H}_{2} \mathrm{O}_{2}$ amounts $\left(<8 \mathrm{~h}\right.$ and 4.4 eq. $\left.\mathrm{H}_{2} \mathrm{O}_{2}\right)$, cleavage of 8 to 12-membered cycloalkenes afforded dicarboxylic acids in less than $30 \%$ yield. Very few exceptions report on the use of larger amounts of $\mathrm{H}_{2} \mathrm{O}_{2}$ or extended reaction times to improve these yields (Table 4, Entries 1,2 and 6). Unfortunately, none of these examples provide clear explanations on the low performances observed with mediumsized cycles. While the nature of the problem was pointed out by Noyori et al. to come from the acid-catalyzed resistance of epoxide intermediates, ${ }^{13,88}$ transannular reactions have been proposed for the first time by Venturello as a probable cause for obtained low oxidative cleavage yields. ${ }^{90,159}$ 
Table 4 Tungsten-based catalytic systems reported for the oxidative cleavage of medium-sized cycloalkenes with $\mathrm{H}_{2} \mathrm{O}_{2}$

\begin{tabular}{|c|c|c|c|c|c|c|c|c|}
\hline Entry & $\begin{array}{c}\text { Tungsten } \\
\text { oxide }\end{array}$ & Substrate & Catalytic system & PTC $^{a}$ & $\begin{array}{l}\text { Reaction } \\
\text { conditions }\end{array}$ & Product & $\underset{b}{\text { Yield }}$ & Ref. \\
\hline 1 & $\mathrm{Na}_{2} \mathrm{WO}_{4}$ & Cyclooctene & $\begin{aligned} & \mathrm{Na}_{2} \mathrm{WO}_{4}+\mathrm{H}_{3} \mathrm{PO}_{4} \\
+ & \mathrm{H}_{2} \mathrm{O}_{2} 30 \% \text { (15 eq.) }\end{aligned}$ & Varisoft $222{ }^{\circledR}{ }^{d}$ & $90^{\circ} \mathrm{C}, 24 \mathrm{~h}$ & Suberic acid & $28 \%^{c}$ & 126 \\
\hline 2 & & Cyclododecene & $\begin{aligned} & \mathrm{Na}_{2} \mathrm{WO}_{4}+\mathrm{H}_{3} \mathrm{PO}_{4} \\
+ & \mathrm{H}_{2} \mathrm{O}_{2} 30 \% \text { (15 eq.) }\end{aligned}$ & Varisoft $222{ }^{\otimes} d$ & $90^{\circ} \mathrm{C}, 24 \mathrm{~h}$ & $\begin{array}{l}\text { Dodecanedioïc } \\
\text { acid }\end{array}$ & $4 \%^{c}$ & 126 \\
\hline 3 & & Cyclooctene & $\mathrm{Na}_{2} \mathrm{WO}_{4}+\mathrm{H}_{2} \mathrm{O}_{2} 35 \%$ (4.4 eq.) & $\mathrm{Oct}_{3} \mathrm{MeN}^{+} \mathrm{HSO}_{4}^{-}$ & $\begin{array}{c}75-90^{\circ} \mathrm{C} \\
8 \mathrm{~h}\end{array}$ & Suberic acid & $9 \%$ & 13,88 \\
\hline 4 & $\begin{array}{l}\left\{\mathrm{PO}_{4}[\mathrm{WO}(\mathrm{O})\right. \\
\left.\left.\quad\left(\mathrm{O}_{2}\right)_{2}\right]_{4}\right\}^{3-}\end{array}$ & Cyclooctene & $\begin{array}{c}{\left[\left(\mathrm{C}_{8} \mathrm{H}_{17}\right)_{3} \mathrm{NCH}_{3}\right]_{3} \mathrm{PO}_{4}\left[\mathrm{WO}(\mathrm{O})\left(\mathrm{O}_{2}\right)_{2}\right]_{4}+} \\
\left.\mathrm{H}_{2} \mathrm{O}_{2} 40 \% \text { (2.75 eq. }\right)\end{array}$ & $\mathrm{Oct}_{3} \mathrm{MeN}^{+} \mathrm{Cl}^{-\mathrm{e}}$ & $85^{\circ} \mathrm{C}, 7 \mathrm{~h}$ & Suberic acid & $24 \%$ & 90 \\
\hline 5 & & Cyclodecene & $\begin{array}{c}{\left[\left(\mathrm{C}_{8} \mathrm{H}_{17}\right)_{3} \mathrm{NCH}_{3}\right]_{3} \mathrm{PO}_{4}\left[\mathrm{WO}(\mathrm{O})\left(\mathrm{O}_{2}\right)_{2}\right]_{4}+} \\
\mathrm{H}_{2} \mathrm{O}_{2} 40 \% \text { (2.75 eq.) }\end{array}$ & $\mathrm{Oct}_{3} \mathrm{MeN}^{+} \mathrm{Cl}^{-\mathrm{e}}$ & $85^{\circ} \mathrm{C}, 7 \mathrm{~h}$ & Sebacic acid & $<1 \%$ & 90 \\
\hline 6 & & Cyclooctene & $\begin{array}{c}{\left[\mathrm{Bu}_{4} \mathrm{~N}\right]_{3} \mathrm{PO}_{4}\left[\mathrm{WO}(\mathrm{O})\left(\mathrm{O}_{2}\right)_{2}\right]_{4}} \\
+\mathrm{H}_{2} \mathrm{O}_{2} 30 \% \text { (8 eq.) }\end{array}$ & $\mathrm{Bu}_{4} \mathrm{~N}^{+} \mathrm{F}^{-}$ & $85^{\circ} \mathrm{C}, 3 \mathrm{~h}$ & Suberic acid & $60 \%{ }^{c}$ & 121 \\
\hline
\end{tabular}




\subsection{Transannular reactions}

Transannular reactions are described by Cope as "the formation of a full bond between atoms on opposite sides of the ring, or reactions which occur on an atom activated only by the proximity in space of a functional group located across the ring". ${ }^{159}$ They have been extensively studied by Cope et al. for seven and eight-membered rings ${ }^{159-162}$ and Prelog et al. for ten membered rings ${ }^{163}$.

The main explanation for the poor results observed with the oxidation of medium-size cycloalkenes lies on the side reactions involving the epoxide intermediate.

The first observation of a transannular reaction during an oxidation process was made during cis-cyclooctene hydroxylation by performic acid. After saponification of the produced formates, the expected trans-1,2-cyclooctanediol had been produced along with non-negligible amounts of an unexpected cis-1,4 diol (Scheme 23). ${ }^{159,161}$ The formation of this by-product originated from the solvolysis with formic acid of the cyclooctene oxide intermediate. Here, the particular conformation of cyclooctene oxide is responsible for the spatial proximity of non-adjacent hydrogen atoms. More specifically, the presence of the hydrogen atoms adjacent to the oxirane ring would explain the direct reaction on the epoxide mainly through a 1,5 hydride shift following the simultaneous solvent addition on the $\mathrm{C}_{6}$ position (Schemes 23 and 24). This trend is also enhanced by the solvent nature and its acidity. Indeed, more detailed studies on the cyclooctene oxide solvolysis showed that the more acid the solvent, the more transannular products formed. ${ }^{159,161}$ This observation can be attributed to a decreased nucleophilic nature of the solvent letting the transannular hydride ion migration to proceed. ${ }^{159}$
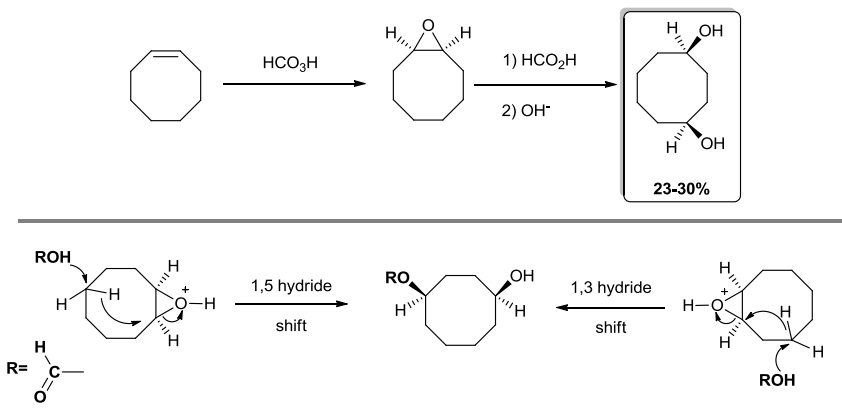

Scheme 23: Formation of cis-1,4 diol product upon formic acid solvolysis of cyclooctene oxide (upward) and mechanism of responsible transannular permission from the Royal Society of Chemistry).

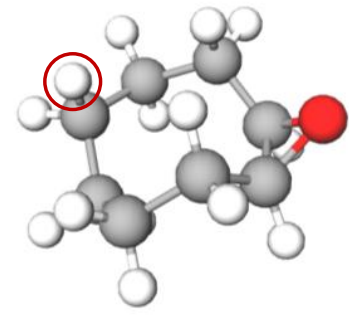

Scheme 24: 3-dimensionnal representation of 1,2-epoxycyclooctane molecule (hydrogen atom sterically adjacent to epoxide ring is circled in red).
Such observations on transannular reactions on medium-sized cycloalkenes are consistent with the information obtained during their oxidative cleavage with the $\mathrm{W}-\mathrm{H}_{2} \mathrm{O}_{2}$ system. For instance, a study by Venturello et al. revealed that 1,4cyclooctanedione is the major neutral by-product detected during the cyclooctene oxidative cleavage. ${ }^{90}$ This compound is an indirect evidence of the formation of undesired 1,4-diol, which is further oxidized into the 1,4-dione by $\mathrm{H}_{2} \mathrm{O}_{2}$. Moreover, the observed low yields for the long chain dicarboxylic acids may be explained by the classically used very acidic conditions required to form the active form of the tungstate catalyst that also favour the formation of transannular products.

Hence, the main challenge chemists have to address for the tungsten-based oxidative cleavage of medium-sized cycloalkenes with $\mathrm{H}_{2} \mathrm{O}_{2}$ is to avoid the formation of problematic epoxide intermediate. Such synthetic route is illustrated with the use of alternative oxidizing systems such as

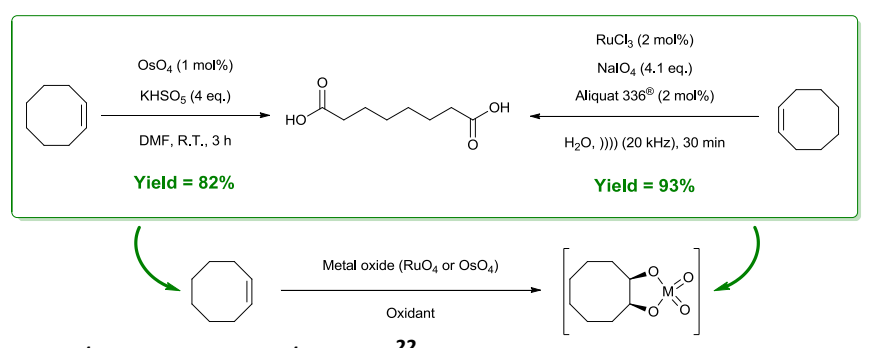

$\mathrm{RuO}_{4} / \mathrm{NaIO}_{4}$ or $\mathrm{OsO}_{4} /$ Oxone. $^{22}$

Scheme 25: Example $e_{65}$ of successful $\mathrm{RuO}_{4}$ and $\mathrm{OsO}_{4}$-mediated cyclooctene oxidative cleavages.

Indeed, in the presence of these specific catalytic systems, the efficient oxidative cleavage of medium-sized rings to the corresponding dicarboxylic acid was performed in excellent yields under mild reaction conditions (Scheme 25). ${ }^{164,165}$ It is worth noting that, from a mechanistic point of view, the common point of ruthenium and osmium oxides is the formation of cyclic peroxometalate ester during the reaction. This complex enables the direct formation of cis-1,2 diols or dialdehydes, avoiding the epoxide intermediates. ${ }^{164,166-168}$ Future trends in the developments of $\mathrm{W}-\mathrm{H}_{2} \mathrm{O}_{2}$ systems would thus focus on the direct formation of the diol intermediate in order to replace efficient but harmful $\mathrm{RuO}_{4} / \mathrm{NalO}_{4}$ or $\mathrm{OsO}_{4} /$ Oxone systems to reach high dicarboxylic acid yields from medium-sized cyclooolefins.

\section{Conclusion and perspective}

The oxidative cleavage of cycloalkenes by hydrogen peroxide has witnessed a growing interest for the sustainable synthesis of dicarboxylic acids. Thanks to the low environmental impact of this oxidant, the $\mathrm{H}_{2} \mathrm{O}_{2}$-mediated oxidation reaction has been widely studied in order to enhance the environmental performances of the current oxidative cleavage processes that involve energy-consuming conditions and harmful oxidants. To 
this aim, various transition metal-based catalysts have been investigated to perform the reaction in the presence of $\mathrm{H}_{2} \mathrm{O}_{2}$. Transition metals such as titanium, chromium, rhenium, ruthenium, manganese and molybdenum have been reported in the literature but most studies relate tungsten-based catalysts as the most environmentally-friendly and efficient ones.

A great emphasis on tungsten-based catalysts led to the development of a large variety of $\mathrm{W}-\mathrm{H}_{2} \mathrm{O}_{2}$ oxidizing systems to perform eco-friendly oxidative cleavages: from tungsten supported heterogeneous catalysts, to homogeneous ones based on polyoxometalates or tungstates, in combination with Phase Transfer Catalysts, ionic liquids or organic acids. Over time, their design gradually integrated the 12 principles of green chemistry to lead to simpler and more efficient systems: progressive removal of solvents, design of simple catalytic systems of low toxicity and decrease of both reaction time and amount of hydrogen peroxide used. Among the developed systems, the ones involving tungstate-based catalysts and catalytic amounts of inorganic acid additives were proven the most efficient in terms of yield, and were up-scaled up to $5,000 \mathrm{~L}$.

As disclosed in this review, despite the high efficiency exhibited by the $\mathrm{W}-\mathrm{H}_{2} \mathrm{O}_{2}$ catalytic systems, their excellent performances are restricted to small-sized cycloalkenes. Indeed, low oxidative cleavage results are observed when tungsten-based catalysts are applied to 8 to 12 -membered cycloolefins. Indeed, in the latter cases, the unavoidable epoxide intermediate formation allows transannular reactions to proceed leading to high amounts of non-desirable byproducts. Hence, the main challenge of such systems will require to prevent the epoxide intermediates formation. Today, systems based on ruthenium and osmium proved to overcome the limits reached with medium-sized cycloolefins by directly forming 1,2-diol derivative. Unfortunately, they still involve expensive and toxic catalysts with waste generating oxidants.

Non-conventional activation techniques would thus constitute a new opportunity to allow switching W-based oxidative cleavage mechanism and improve previous results. Some of them such as enzymatic catalysis or supercritical $\mathrm{CO}_{2}$ were already investigated but only led to aldehydes or lack of selectivity. ${ }^{28,169,170}$ Among non-conventional techniques, ultrasound is part of the most promising ones. Indeed, the cavitation phenomenon occurring through propagation of ultrasonic waves into an elastic media leads to modifications of different nature. Subsequent nucleation, growth and brutal collapse of micrometric gaseous bubbles under ultrasonic irradiation create extreme local conditions with extremely high temperatures (up to 5,000 K) and pressures (up to 1,000 atm). Such implosions result in both important physical (micro-jets, shockwaves, shearing forces) and chemical effects (solvent sonolysis, radical production). ${ }^{171,172}$ Ultrasound-assisted syntheses highlighted the multiple benefits of this technique to better understand and improve $\mathrm{H}_{2} \mathrm{O}_{2}$-mediated oxidations. $^{173-177}$

To date, the only example of ultrasound-mediated oxidative cleavage involve the use of the $\mathrm{RuCl}_{3} / \mathrm{NaIO}_{4}$ system in combination with low frequency ultrasound. Physical effects produced under $20 \mathrm{kHz}$ irradiation proved to promote mixing between non-miscible reactants for the biphasic oxidative cleavage of cyclohexene and cyclooctene. Excellent dicarboxylic acid yields were reported under only $30 \mathrm{~min}$ of low frequency ultrasound (Scheme 25). ${ }^{165}$ Hence, the synergistic use of hydrogen peroxide and ultrasound opens new perspectives to oxidative cleavage thanks to the chemical effects brought by ultrasound. Indeed, submitting an aqueous solution of hydrogen peroxide to ultrasound would result in splitting $\mathrm{H}_{2} \mathrm{O}_{2}$ into $\mathrm{HO}^{\circ}$ radicals. Such reactive species would thus avoid the formation of problematic epoxide by forming directly the desired 1,2-diol intermediate through addition on

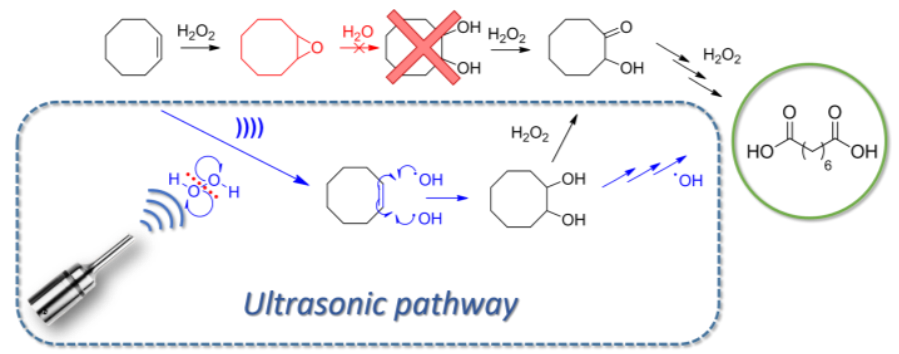

C-C double bond (Scheme 26).

Scheme 26: Hypothesis of $\mathrm{H}_{2} \mathrm{O}_{2}$-mediated oxidative cleavage of medium-sized cycloalkenes under ultrasound: cis-cyclooctene example.

The potential of such reactive species for the selective oxidation of organic compounds have been recently reported for the aerobic oxidation of glucose to glucuronic acid under ultrasound and catalyst-free conditions. Indeed, the formation of $\mathrm{HO}^{\circ}$ and $\mathrm{HOO}^{\circ}$ radicals from $\mathrm{H}_{2} \mathrm{O}$ and $\mathrm{O}_{2}$ under ultrasound is shown to be very important for the the selective oxidation of primary alcohol of glucose with conversion and selectivities above $95 \% .{ }^{178}$

Combination of $\mathrm{W}-\mathrm{H}_{2} \mathrm{O}_{2}$ catalytic systems with ultrasound thus constitutes a promising approach paving the way to a more efficient and sustainable synthesis of dicarboxylic acids through oxidative cleavage.

\section{Conflicts of interest}

There are no conflicts to declare.

\section{Acknowledgements}

Authors are grateful to the Région Auvergne Rhône-Alpes for the financial support through an ARC Environnement doctoral research grant (ARC 2016). They also thank Dr. Marion Chevallier for her help on the design of molecules of the graphical abstract.

\section{Notes and references}


1 J. H. Teles, I. Hermans, G. Franz and R. A. Sheldon, in Ullmann's Encyclopedia of Industrial Chemistry, ed. Wiley-VCH Verlag $\mathrm{GmbH}$ \& Co. KGaA, Wiley-VCH Verlag GmbH \& Co. KGaA, Weinheim, Germany, 2015, pp. 1-103.

2 F. Cavani and J. H. Teles, ChemSusChem, 2009, 2, 508-534.

$3 \mathrm{~K}$. Weissermel and H.-J. Arpe, Industrial organic chemistry, VCH, Weinheim, Germany, 3rd Ed., 1997.

4 G. Strukul, Ed., Catalytic Oxidations with Hydrogen Peroxide as Oxidant, Springer Netherlands, 1992.

5 B. Cornils and P. Lappe, in Ullmann's Encyclopedia of Industrial Chemistry, ed. Wiley-VCH Verlag GmbH \& Co. KGaA, Wiley-VCH Verlag GmbH \& Co. KGaA, Weinheim, Germany, 2000.

6 M. T. Musser, in Ullmann's Encyclopedia of Industrial Chemistry, ed. Wiley-VCH Verlag GmbH \& Co. KGaA, Wiley-VCH Verlag GmbH \& Co. KGaA, Weinheim, Germany, 2000.

7 US2813113 (A), 1957.

8 A. Köckritz and A. Martin, Eur. J. Lipid Sci. Technol., 2008, 110, 812-824.

9 A. Köckritz and A. Martin, Eur. J. Lipid Sci. Technol., 2011, 113, 8391.

10 F. Cavani and S. Alini, in Sustainable Industrial Chemistry, eds. F. Cavani, G. Centi, S. Perathoner and F. Trifir, Wiley-VCH Verlag GmbH \& Co. KGaA, Weinheim, Germany, 2009, pp. 367-425.

11 United States, US2557282A, 1951.

12 J. C. J. Bart and S. Cavallaro, Ind. Eng. Chem. Res., 2015, 54, 146.

13 K. Sato, M. Aoki and R. Noyori, Science, 1998, 281, 1646-1647.

14 C. Bolm, O. Beckmann and O. A. G. Dabard, Angew. Chem. Int. Ed., 1999, 38, 907-909.

15 R. E. Dickinson and R. J. Cicerone, Nature, 1986, 319, 109-115.

16 R. A. Reimer, C. S. Slaten, M. Seapan, M. W. Lower and P. E. Tomlinson, Environ. Prog., 1994, 13, 134-137.

17 A. Shimizu, K. Tanaka and M. Fujimori, Chemosphere - Glob. Change Sci., 2000, 2, 425-434.

18 B. M. Trost, Angew. Chem. Int. Ed. Engl., 1995, 34, 259-281.

19 P. T. Anastas and J. C. Warner, Green chemistry: theory and practice, Oxford University Press, 2000.

20 R. A. Sheldon, in Organic Reactions in Water, ed. U. M. Lindstrm, Blackwell Publishing Ltd, Oxford, UK, 2007, pp. 215235.

21 R. A. Sheldon, Chem. Commun., 2008, 3352.

22 R. A. Sheldon and J. K. Kochi, Metal-catalyzed oxidations of organic compounds: mechanistic principles and synthetic methodology including biochemical processes, Academic Press, New York, 1981.

23 W. S. Trahanovsky, Ed., Oxidation in organic chemistry. D: ..., Acad. Pr, New York, 1982.

24 S. Wolfe, S. K. Hasan and J. R. Campbell, J. Chem. Soc. Chem. Commun., 1970, 1420.

25 P. H. J. Carlsen, T. Katsuki, V. S. Martin and K. B. Sharpless, J. Org. Chem., 1981, 46, 3936-3938.

26 S. Warwel, M. Sojka and M. R. gen Klaas, in Organic Peroxygen Chemistry, ed. W. A. Herrmann, Springer Berlin Heidelberg, Berlin, Heidelberg, 1993, vol. 164, pp. 79-98.

27 B. Zaldman, A. Kisilev, Y. Sasson and N. Garti, J. Am. Oil Chem. Soc., 1988, 65, 611-615.

28 F. G. Mutti, Bioinorg. Chem. Appl., 2012, 2012, 1-13.

29 A. Enferadi Kerenkan, F. Béland and T.-O. Do, Catal Sci Technol, 2016, 6, 971-987.

30 A. Godard, P. de Caro, E. Vedrenne, Z. Mouloungui and S. Thiebaud-Roux, OCL, 2016, 23, D510.
31 N. M. Wilson, D. T. Bregante, P. Priyadarshini and D. W. Flaherty, in Catalysis, eds. J. Spivey and Y.-F. Han, Royal Society of Chemistry, Cambridge, 2017, vol. 29, pp. 122-212.

32 C. W. Jones, Applications of hydrogen peroxide and derivatives, Royal Society of Chemistry, Cambridge, 1999.

33 R. Ciriminna, L. Albanese, F. Meneguzzo and M. Pagliaro, ChemSusChem, 2016, 9, 3374-3381.

34 W. R. Sanderson, in Handbook of Green Chemistry and Technology, eds. J. H. Clark and D. Macquarrie, Blackwell Science Ltd, Oxford, UK, 2002, pp. 258-305.

35 G. Centi and S. Perathoner, Catal. Today, 2003, 77, 287-297.

36 P. Rao and M. Muller, New-York, 2007, vol. 6, pp. 124-135.

37 V. Russo, R. Tesser, E. Santacesaria and M. Di Serio, Ind. Eng. Chem. Res., 2013, 52, 1168-1178.

38 HPPO Technology - Evonik is one of the world's largest producers of hydrogen peroxide - $\mathrm{H} 2 \mathrm{O} 2$, http://h2o2.evonik.com/product/h2o2/en/Pages/hppotechnology.aspx, (accessed November 1, 2017).

39 United States, US6518441B2, 2003.

40 C. P. Horwitz, in Innovations in Green Chemistry and Green Engineering, eds. P. T. Anastas and J. B. Zimmerman, Springer New York, New York, NY, 2013, pp. 247-295.

41 P. Bassler, H.-G. Göbbel and M. Weidenbach, Chem. Eng. Trans., 2010, 571-576.

42 A. Soutelo-Maria, J.-L. Dubois, J.-L. Couturier and G. Cravotto, Catalysts, 2018, 8, 464.

43 D. C. M. Albanese, F. Foschi and M. Penso, Org. Process Res. Dev., 2016, 20, 129-139.

44 S. Van de Vyver and Y. Román-Leshkov, Catal Sci Technol, 2013, 3, 1465-1479.

45 A. Rajagopalan, M. Lara and W. Kroutil, Adv. Synth. Catal., 2013, 355, 3321-3335.

46 F. Chen, T. Wang and N. Jiao, Chem. Rev., 2014, 114, 86138661.

47 A. Rahman, M. Mupa and C. Mahamadi, Catal. Lett., 2016, 146, 788-799.

48 H. Wójtowicz-Młochowska, Arkivoc, 2016, 2017, 12-58.

49 Free Printable Periodic Tables (PDF and PNG),

https://sciencenotes.org/printable-periodic-table/, (accessed June 12,2019$)$.

50 C. Mi, X.-G. Meng, X.-H. Liao and X. Peng, RSC Adv, 2015, 5, 69487-69492.

51 S. R. Hart, D. C. Whitehead, B. R. Travis and B. Borhan, Org. Biomol. Chem., 2011, 9, 4741.

52 O. A. Kholdeeva, A. Y. Derevyankin, A. N. Shmakov, N. N. Trukhan, E. A. Paukshtis, A. Tuel and V. N. Romannikov, J. Mol. Catal. Chem., 2000, 158, 417-421.

53 N. N. Trukhan, A. Yu. Derevyankin, A. N. Shmakov, E. A. Paukshtis, O. A. Kholdeeva and V. N. Romannikov, Microporous Mesoporous Mater., 2001, 44-45, 603-608.

54 S.-O. Lee, R. Raja, K. D. M. Harris, J. M. Thomas, B. F. G. Johnson and G. Sankar, Angew. Chem. Int. Ed., 2003, 42, 1520-1523.

55 A. Alfayate, C. Márquez-Álvarez, M. Grande-Casas, B. BernardoMaestro, M. Sánchez-Sánchez and J. Pérez-Pariente, Catal. Today, 2013, 213, 211-218.

56 M. N. Timofeeva, O. A. Kholdeeva, S. H. Jhung and J.-S. Chang, Appl. Catal. Gen., 2008, 345, 195-200.

57 G. Lapisardi, F. Chiker, F. Launay, J. P. Nogier and J. L. Bonardet, Microporous Mesoporous Mater., 2005, 78, 289-295.

58 M. North and Royal Society of Chemistry (Great Britain), Eds., Sustainable catalysis, Royal Society of Chemistry, Cambridge, UK, 2016. 
59 D. Farrusseng, S. Aguado and C. Pinel, Angew. Chem. Int. Ed. 2009, 48, 7502-7513.

60 G. Ferey, Science, 2005, 309, 2040-2042.

61 Z. Saedi, S. Tangestaninejad, M. Moghadam, V. Mirkhani and I. Mohammadpoor-Baltork, Catal. Commun., 2012, 17, 18-22.

62 M. Nourian, F. Zadehahmadi, R. Kardanpour, S.

Tangestaninejad, M. Moghadam, V. Mirkhani and I.

Mohammadpoor-Baltork, Appl. Organomet. Chem., DOI:10.1002/aoc.3957.

63 S. Langård and M. Costa, in Handbook on the Toxicology of Metals, Elsevier, 2015, pp. 717-742.

64 US3646130 A, 1972.

65 F. E. Kühn, A. Scherbaum and W. A. Herrmann, J. Organomet. Chem., 2004, 689, 4149-4164.

66 K. R. Jain and F. E. Kühn, J. Organomet. Chem., 2007, 692, 55325540.

67 J. Y. Wang, M. D. Zhou, Y. G. Yuan, N. H. Fu and S. L. Zang, Russ. J. Gen. Chem., 2015, 85, 2378-2385.

68 A. Johnstone, P. J. Middleton, W. R. Sanderson, M. Service and P. R. Harrison, in Studies in Surface Science and Catalysis, Elsevier, 1994, vol. 82, pp. 609-614.

69 C.-M. Che, W.-P. Yip and W.-Y. Yu, Chem. - Asian J., 2006, 1, 453-458.

70 A. K. Sahu, D. K. Dash, K. Mishra, S. P.Mishra, R. Yadav and P. Kashyap, Noble Precious Met. - Prop. Nanoscale Eff. Appl., DOI:10.5772/intechopen.76393.

71 C. D. Brooks, L. Huang, M. McCarron and R. A. W. Johnstone, Chem. Commun., 1999, 37-38.

72 P.-P. Knops-Gerrits, D. De Vos, F. Thibault-Starzyk and P. A. Jacobs, Nature, 1994, 369, 543-546.

73 V. Escande, E. Petit, L. Garoux, C. Boulanger and C. Grison, ACS Sustain. Chem. Eng., 2015, 3, 2704-2715.

74 M. Amini, M. M. Haghdoost and M. Bagherzadeh, Coord. Chem. Rev., 2013, 257, 1093-1121.

75 N. J. Campbell, A. C. Dengel, C. J. Edwards and W. P. Griffith, J. Chem. Soc. Dalton Trans., 1989, 1203.

76 M. H. Dickman and M. T. Pope, Chem. Rev., 1994, 94, 569-584.

77 J. Alcañiz-Monge, G. Trautwein and A. Garcia-Garcia, J. Mol. Catal. Chem., 2014, 394, 211-216.

78 M. G. Buonomenna, G. Golemme, M. P. De Santo and E. Drioli, Org. Process Res. Dev., 2010, 14, 252-258.

79 W.-L. Dai, J. Ding, Q. Zhu, R. Gao and X. Yang, in Catalysis, Royal Society of Chemistry, Cambridge, 2016, vol. 28, pp. 1-27.

80 National Research Council (U.S.)., Handbook of toxicology., Saunders, Philadelphia, 1956.

81 P. E. Leffler and G. Kazantzis, in Handbook on the Toxicology of Metals, Elsevier, 2015, pp. 1297-1306.

82 E. Lassner, W.-D. Schubert, E. Lüderitz and H. U. Wolf, in Ullmann's Encyclopedia of Industrial Chemistry, ed. Wiley-VCH Verlag GmbH \& Co. KGaA, Wiley-VCH Verlag GmbH \& Co. KGaA, Weinheim, Germany, 2000.

83 L. Salles, C. Aubry, R. Thouvenot, F. Robert, C. DoremieuxMorin, G. Chottard, H. Ledon, Y. Jeannin and J. M. Bregeault, Inorg. Chem., 1994, 33, 871-878.

84 W. P. Griffith, Transit. Met. Chem., 1991, 16, 548-552.

85 A. J. Bailey, W. P. Griffith and B. C. Parkin, J. Chem. Soc. Dalton Trans., 1995, 1833.

86 Y. Ishii, K. Yamawaki, T. Ura, H. Yamada, T. Yoshida and M. Ogawa, J. Org. Chem., 1988, 53, 3587-3593.

87 K. Sato, M. Aoki, M. Ogawa, T. Hashimoto, D. Panyella and R. Noyori, Bull. Chem. Soc. Jpn., 1997, 70, 905-915.

88 R. Noyori, M. Aoki and K. Sato, Chem. Commun., 2003, 1977.
89 C. Venturello and M. Ricci, J. Org. Chem., 1986, 51, 1599-1602.

90 E. Antonelli, R. D'Aloisio, M. Gambaro, T. Fiorani and C.

Venturello, J. Org. Chem., 1998, 63, 7190-7206.

91 L. Knof, Justus Liebigs Ann. Chem., 1962, 656, 183-189.

92 G. M. Rubottom, J. M. Gruber, R. K. Boeckman, M. Ramaiah and

J. B. Medwid, Tetrahedron Lett., 1978, 19, 4603-4606.

93 P. Jin, L. Zhu, D. Wei, M. Tang and X. Wang, Comput. Theor. Chem., 2011, 966, 207-212.

94 C. Venturello and M. Gambaro, J. Org. Chem., 1991, 56, 59245931.

95 K. Sato, M. Aoki, J. Takagi and R. Noyori, J. Am. Chem. Soc., 1997, 119, 12386-12387.

96 K. Fujitani, T. Mizutani, T. Oida and T. Kawase, J. Oleo Sci., 2009, 58, 323-328.

97 C. Venturello, E. Alneri and M. Ricci, J. Org. Chem., 1983, 48, 3831-3833.

98 D. C. Duncan, R. C. Chambers, E. Hecht and C. L. Hill, J. Am. Chem. Soc., 1995, 117, 681-691.

99 M. J. N. Pourbaix and N. de Zoubov, Atlas d'equilibres electrochimiques, Gauthier-Villars, Paris, 1963.

100A. C. Dengel, W. P. Griffith and B. C. Parkin, J. Chem. Soc. Dalton Trans., 1993, 2683-2688.

101A. Enferadi-Kerenkan, T.-O. Do and S. Kaliaguine, Catal. Sci. Technol., 2018, 8, 2257-2284.

102C.-Y. Cheng, K.-J. Lin, M. R. Prasad, S.-J. Fu, S.-Y. Chang, S.-G. Shyu, H.-S. Sheu, C.-H. Chen, C.-H. Chuang and M.-T. Lin, Catal. Commun., 2007, 8, 1060-1064.

103Z. Bohström, I. Rico-Lattes and K. Holmberg, Green Chem., 2010, 12, 1861.

104M. Vafaeezadeh and M. Mahmoodi Hashemi, Catal. Commun., 2014, 43, 169-172.

105L. Meng, S. Zhai, Z. Sun, F. Zhang, Z. Xiao and Q. An, Microporous Mesoporous Mater., 2015, 204, 123-130.

106Y. Yoshimura, Y. Ogasawara, K. Suzuki, K. Yamaguchi and N.

Mizuno, Catal Sci Technol, 2017, 7, 1662-1670.

107I. V. Kozhevnikov, Chem. Rev., 1998, 98, 171-198.

108S.-S. Wang and G.-Y. Yang, Chem. Rev., 2015, 115, 4893-4962.

109C. L. Hill, in Catalytic Oxidations with Hydrogen Peroxide as Oxidant, ed. G. Strukul, Springer Netherlands, Dordrecht, 1992, vol. 9, pp. 253-280.

110C. Venturello, R. D'Aloisio, J. C. J. Bart and M. Ricci, J. Mol. Catal., 1985, 32, 107-110.

111Catherine. Aubry, Genevieve. Chottard, Nicole. Platzer, J. Marie. Bregeault, Rene. Thouvenot, Francoise. Chauveau, Catherine. Huet and Henry. Ledon, Inorg. Chem., 1991, 30, 4409-4415.

112F. A. Almeida Paz, F. L. Sousa, P. C. R. Soares-Santos, A. M. V. Cavaleiro, H. I. S. Nogueira, J. Klinowski and T. Trindade, Acta Crystallogr. Sect. E Struct. Rep. Online, 2004, 60, m1-m5.

113 W. Zhu, H. Li, X. He, Q. Zhang, H. Shu and Y. Yan, Catal. Commun., 2008, 9, 551-555.

114C. L. Hill and C. M. Prosser-McCartha, Coord. Chem. Rev., 1995, 143, 407-455.

115C. Venturello and R. D'Aloisio, J. Org. Chem., 1988, 53, 15531557.

116L. Hua, Y. Qiao, H. Li, B. Feng, Z. Pan, Y. Yu, W. Zhu and Z. Hou, Sci. China Chem., 2011, 54, 769.

117Y. Ding, W. Zhao, H. Hua and B. Ma, Green Chem., 2008, 10, 910-913.

118EP0122804 (A1), 1984.

119 H. Chen, W.-L. Dai, X.-L. Yang, R. Gao, Y. Cao, H. Li and K. Fan, Appl. Catal. Gen., 2006, 309, 62-69. 
120H. Chen, W.-L. Dai, R. Gao, Y. Cao, H. Li and K. Fan, Appl. Catal. Gen., 2007, 328, 226-236.

121Z. P. Pai, A. G. Tolstikov, P. V. Berdnikova, G. N. Kustova, T. B. Khlebnikova, N. V. Selivanova, A. B. Shangina and V. G. Kostrovskii, Russ. Chem. Bull., 2005, 54, 1847-1854.

122C. M. Starks, J. Am. Chem. Soc., 1971, 93, 195-199.

123C. M. Starks and C. Liotta, in Phase Transfer Catalysis, Elsevier, 1978, pp. 57-90.

124C. M. Starks and C. Liotta, in Phase Transfer Catalysis, Elsevier, 1978, pp. 13-56.

125C. M. Starks and C. Liotta, in Phase Transfer Catalysis, Elsevier, 1978, pp. 298-329.

126R. Kadyrov and D. Hackenberger, Top. Catal., 2014, 57, 13661371.

127P. Blach, Z. Böstrom, S. Franceschi-Messant, A. Lattes, E. Perez and I. Rico-Lattes, Tetrahedron, 2010, 66, 7124-7128.

128G. Lesage, I. Quesada Peñate, P. Cognet and M. Poux, Int. J. Chem. React. Eng., , DOI:10.1515/1542-6580.2955.

129S. Borukhova and V. Hessel, in Process Intensification for Green Chemistry, eds. K. Boodhoo and A. Harvey, John Wiley \& Sons, Ltd, Chichester, UK, 2013, pp. 91-156.

130 M. Shang, T. Noël, Q. Wang and V. Hessel, Chem. Eng. Technol., 2013, 36, 1001-1009.

131 H. P. L. Gemoets, Y. Su, M. Shang, V. Hessel, R. Luque and T. Noël, Chem. Soc. Rev., 2016, 45, 83-117.

132WO/2009/109857, 2009.

133G. Hong, J. Heng and L. U. Zhen-Bo, 高等学校化学学报, 2000, 21, 1121-1123.

134K. Sato, M. Aoki, M. Ogawa, T. Hashimoto and R. Noyori, J. Org. Chem., 1996, 61, 8310-8311.

135Y. Deng, Z. Ma, K. Wang and J. Chen, Green Chem., 1999, 1, 275-276.

136P. Wasserscheid and T. Welton, Eds., Ionic Liquids in Synthesis, Wiley-VCH Verlag GmbH \& Co. KGaA, Weinheim, Germany, 2007.

137H. Olivier-Bourbigou, L. Magna and D. Morvan, Appl. Catal. Gen., 2010, 373, 1-56.

138J. P. Hallett and T. Welton, Chem. Rev., 2011, 111, 3508-3576.

139J. Muzart, Adv. Synth. Catal., 2006, 348, 275-295.

140L. Zhu and C. Hu, in Ionic Liquids - New Aspects for the Future, ed. J. Kadokawa, InTech, 2013.

$141 \mathrm{M}$. Vafaeezadeh, M. M. Hashemi and M. Shakourian-Fard, Catal. Commun., 2012, 26, 54-57.

142 M. Vafaeezadeh and M. Mahmoodi Hashemi, RSC Adv, 2015, 5, 31298-31302.

143 M. Vafaeezadeh and M. M. Hashemi, Process Saf. Environ. Prot., 2016, 100, 203-207.

144M. Vafaeezadeh and M. M. Hashemi, Chem. Eng. J., 2013, 221, 254-257.

145 H. Jiang, H. Gong, Z. Yang, X. Zhang and Z. Sun, React. Kinet. Catal. Lett., 2002, 75, 315-321.

146J. Gui, D. Liu, X. Cong, X. Zhang, H. Jiang, Z. Hu and Z. Sun, J. Chem. Res., 2005, 2005, 520-522.

147S. E. Jacobson, D. A. Muccigrosso and F. Mares, J. Org. Chem., 1979, 44, 921-924.

148W. Zhu, H. Li, X. He, H. Shu and Y. Yan, J. Chem. Res., 2006, 2006, 774-775.

149H. Li, W. Zhu, X. He, Q. Zhang, J. Pan and Y. Yan, React. Kinet. Catal. Lett., 2007, 92, 319-327.

150 M. J. Ford, H. Kohlhepp, S. Miller, S. Riess, J. P. Schmidt and L. Wisplinghoff, Org. Process Res. Dev., 2011, 15, 883-885.

151S. Ren, Z. Xie, L. Cao, X. Xie, G. Qin and J. Wang, Catal. Commun., 2009, 10, 464-467.
152D. Jingfa, X. Xinhua, C. Haiying and J. Anren, Tetrahedron, 1992, 48, 3503-3514.

153T. Oguchi, T. Ura, Y. Ishii and M. Ogawa, Chem. Lett., 1989, 18, 857-860.

154K. Fujitani, T. Mizutani, T. Oida and T. Kawase, J. Oleo Sci., 2009, 58, 37-42.

155M. Damm, B. Gutmann and C. O. Kappe, ChemSusChem, 2013, 6, 978-982.

156P. Jin, Z. Zhao, Z. Dai, D. Wei, M. Tang and X. Wang, Catal. Today, 2011, 175, 619-624.

157Y. Wen, X. Wang, H. Wei, B. Li, P. Jin and L. Li, Green Chem., 2012, 14, 2868.

158C. Ye, P. Jin, J. Liu, Y. Wen, H. Wei, X. Zheng, X. Wang and B. Li, Ind. Eng. Chem. Res., 2013, 52, 3600-3606.

159A. C. Cope, M. M. Martin and M. A. McKervey, Q. Rev. Chem. Soc., 1966, 20, 119.

160A. C. Cope, A. Fournier and H. E. Simmons, J. Am. Chem. Soc., 1957, 79, 3905-3909.

161A. C. Cope, S. W. Fenton and C. F. Spencer, J. Am. Chem. Soc., 1952, 74, 5884-5888.

162A. C. Cope, T. A. Liss and G. W. Wood, J. Am. Chem. Soc., 1957, 79, 6287-6292.

163V. Prelog and K. Schenker, Helv. Chim. Acta, 1952, 35, 20442053.

164B. R. Travis, R. S. Narayan and B. Borhan, J. Am. Chem. Soc., 2002, 124, 3824-3825.

165S. Rup, M. Sindt and N. Oget, Tetrahedron Lett., 2010, 51, 31233126.

166L. M. Berkowitz and P. N. Rylander, J. Am. Chem. Soc., 1958, 80, 6682-6684.

167M. Rüsch, Gen. Klaas, P. Bavaj and S. Warwel, Fett Wiss. Technol. Sci. Technol., 1995, 97, 359-367.

168R. Pappo, D. S. Allen, Jr., R. U. Lemieux and W. S. Johnson, J. Org. Chem., 1956, 21, 478-479.

169C. E. Paul, A. Rajagopalan, I. Lavandera, V. Gotor-Fernández, W. Kroutil and V. Gotor, Chem. Commun., 2012, 48, 3303.

170E. J. Beckman, Environ. Sci. Technol., 2003, 37, 5289-5296.

171J.-L. Luche, Synthetic Organic Sonochemistry, Springer US, Boston, MA, 1998.

172T. J. Mason, Sonochemistry, Oxford Univ. Press, Oxford, 1999.

173 N. N. Mahamuni, P. R. Gogate and A. B. Pandit, Ind. Eng. Chem. Res., 2006, 45, 98-108.

174G. Chatel, C. Goux-Henry, A. Mirabaud, T. Rossi, N. Kardos, B. Andrioletti and M. Draye, J. Catal., 2012, 291, 127-132.

175D. Rinsant, G. Chatel and F. Jérôme, ChemCatChem, 2014, 6, 3355-3359.

176F. Napoly, N. Kardos, L. Jean-Gérard, C. Goux-Henry, B. Andrioletti and M. Draye, Ind. Eng. Chem. Res., 2015, 54, 60466051.

177T. Cousin, G. Chatel, N. Kardos, B. Andrioletti and M. Draye, Ultrason. Sonochem., 2019, 53, 120-125.

178P. N. Amaniampong, A. Karam, Q. T. Trinh, K. Xu, H. Hirao, F. Jérôme and G. Chatel, Sci. Rep., 7, 40650, DOI:10.1038/srep40650. 